NBER WORKING PAPER SERIES

\title{
FAMILY STATUS TRANSITIONS, LATENT HEALTH, AND THE POST-RETIREMENT EVOLUTION OF ASSETS
}

\author{
James M. Poterba \\ Steven F. Venti \\ David A. Wise \\ Working Paper 15789 \\ http://www.nber.org/papers/w15789 \\ NATIONAL BUREAU OF ECONOMIC RESEARCH \\ 1050 Massachusetts Avenue \\ Cambridge, MA 02138 \\ February 2010
}

This research was supported by the U.S. Social Security Administration through grant \#10-P-98363-1-05 to the National Bureau of Economic Research as part of the SSA Retirement Research Consortium. Funding was also provided through grant number P01 AG005842 from the National Institute on Aging. The findings and conclusions expressed are solely those of the authors and do not represent the views of SSA, any agency of the Federal Government, or the NBER. We have benefited from the comments of participants in the Conference on the Economics of Aging in May 2009, particularly our discussant David Laibson, and from two reviewers for the University of Chicago Press. The views expressed herein are those of the authors and do not necessarily reflect the views of the National Bureau of Economic Research.

At least one co-author has disclosed a financial relationship of potential relevance for this research. Further information is available online at http://www.nber.org/papers/w15789.ack

NBER working papers are circulated for discussion and comment purposes. They have not been peerreviewed or been subject to the review by the NBER Board of Directors that accompanies official NBER publications.

(C) 2010 by James M. Poterba, Steven F. Venti, and David A. Wise. All rights reserved. Short sections of text, not to exceed two paragraphs, may be quoted without explicit permission provided that full credit, including $\odot$ notice, is given to the source. 
Family Status Transitions, Latent Health, and the Post-Retirement Evolution of Assets

James M. Poterba, Steven F. Venti, and David A. Wise

NBER Working Paper No. 15789

February 2010

JEL No. E21,J14

\begin{abstract}
$\underline{\text { ABSTRACT }}$
We consider the evolution of assets after retirement. We ask whether total assets--including housing equity, personal retirement accounts, and other financial assets--tend to be husbanded for a rainy day and drawn down primarily at the time of precipitating shocks, or whether they are drawn down throughout the retirement period. We focus on the relationships between family status transitions, "latent" health status, and the evolution of assets. Our analysis is based primarily on longitudinal data from the HRS and AHEAD cohorts of the Health and Retirement Study. We find that the evolution of assets is strongly related to family status transitions. For both single individuals and married couples who do not experience a death or divorce, total assets increase well into old age. In contrast, individuals in married couples that experience a family status transition, either a death or a divorce, exhibit much slower asset growth and often experience a large decline in asset values at the time of the transition. In addition, the level and evolution of assets is very strongly related to health, measured by a latent health index. For example, for continuing two-person HRS households between the ages of 56 and 61 in 1992 the ratio of assets of households in the top health quintile to the assets of those in the bottom quintile was 1.7 in 1992. It had increased to 2.2 by the end of 2006 .
\end{abstract}

James M. Poterba

NBER

1050 Massachusetts Ave

Cambridge, MA 02138

poterba@mit.edu

Steven F. Venti

Department of Economics

6106 Rockefeller Center

Dartmouth College

Hanover, NH 03755

and NBER

steven.f.venti@dartmouth.edu
David A. Wise

Harvard University

1050 Massachusetts Avenue

Cambridge, MA 02138-5398

and NBER

dwise@nber.org 
Personal retirement accounts are one of the primary means of saving for retirement in the U.S. Since the advent of these accounts in the early 1980s, a great deal of attention has been directed to the accumulation of retirement assets in these accounts. Much less attention has been directed to the drawdown of assets under a regime in which personal accounts play an increasingly important role. When private retirement saving was dominated by employer-provided defined benefit plans, benefits were typically dispersed in the form of annuities. Under the personal account regime only a very small fraction of retirement assets are annuitized, and the drawdown of assets is largely self-directed.

The increasing importance of personal retirement accounts raises a number of important questions. One is how the evolution of assets in retirement is related to precipitating "shocks," such as health events, widowhood, divorce, and nursing home entry. All of these shocks may have financial consequences. Another is how the distribution of assets evolves with age. What is the likelihood of a household being unable to cover the cost of health shocks or the cost of a change in family status? A third question is how alternative methods of managing asset drawdown may affect financial well-being. In particular, how does the current largely "self-directed" system compare to a more "managed" system such as one featuring partial or full annuitization of personal account assets? Finally, how do recent and anticipated future developments, such as the recent decline in financial asset values, rising retirement ages, and the anticipated growth in personal retirement assets in future decades, affect the ability of households to meet health and family status shocks?

The principle aim of this paper is to set out a data framework that can support analysis of these questions. We focus our analysis on the extent to which the drawdown of assets is triggered by shocks to family status and how the evolution of assets is related to health status.

Venti and Wise $(2001,2004)$ considered the drawdown of home equity in retirement. They found that, on average, home equity increased through age 70 and declined slightly (1.76 percent per year) thereafter. Almost all of this average decline for older retirees could be accounted for by the decline in home equity among households experiencing shocks to family status, like death of a spouse or entry into a nursing home. There was little decline for households that did not experience shocks, which suggested that home equity was typically not used to support general consumption in retirement but instead was conserved for a "rainy day." Megbolugbe, Sa-Aadu, and Shilling $(1997,1999)$ and Banks, Blundell, Oldfield and Smith (2007) also found that the drawdown of assets was greatest at times of change in family status. Davidoff (2007) concludes that households may preserve their home equity to finance potentially large health expenses, using home equity as an informal source of long-term care insurance.

In Poterba, Venti, and Wise (2009), we found that IRA and 401(k) assets tend to be conserved and that less than one-quarter of all account holders withdraw assets from these accounts before age $70 \frac{1}{2}$, the age at which they 
become subject to minimum distribution requirements. Even among those who made withdrawals before age $70 \frac{1}{2}$, the amounts averaged less that 2 percent of the balance. Holden (2009) found that only 21.4 percent of IRA-owning households age 59 to 69 made a withdrawal in 2008. This evidence suggests that personal retirement plan assets, like home equity, are husbanded in retirement - at least by many households.

Most previous research on retirement saving has focused on asset accumulation, not the draw-down of assets after retirement. A notable exception is the study by Hurd and Rohwedder (2006), which tracks wealth changes and household consumption in panel data. There have also been a number of studies, summarized in Hurst (2008), of household consumption after retirement. But the consumption literature in most cases does not examine changes in asset holdings.

Among the studies that do focus on changes in wealth, there has been limited attention to shocks to family status. Hurd (2002), using HRS data, finds that most components of the portfolios of the elderly grow after retirement. The exception, he finds, is that the probability of owning a home declines after age 80. Coile and Milligan (2009), also studying HRS data, find that holdings of housing and vehicles decline with age but that holdings of financial assets increase. They find that shocks, particularly widowhood, are coincident with asset drawdown, and in particular with a decline in home ownership. They do not compare the age profile of housing and vehicle ownership for those with, and without, shocks to health and family status. Haveman et. al. (2005) consider whether assets at retirement are sufficient to maintain for the next ten years the earnings replacement rate at retirement, using the SSA's New Beneficiary Survey. They find that although the median replacement rate remains constant, there is substantial variation over time. Over a fifth of the households judged to have adequate saving at retirement fell below their retirement-age replacement rate by ten years after retirement. Lupton and Smith (2000) explore the relationship between family status and wealth using the first wave of the HRS and three waves of the PSID. Their cross-sectional analysis using the HRS shows that there are large wealth differences by marital status. Their longitudinal analysis using the PSID shows that assets increase for continuously married families, are unchanged for divorced or separated families, and decline for widowed families. The PSID results pertain to households that are younger than the HRS households that we study, and thus the estimated changes in assets reflect differences in pre-retirement saving rather than post-retirement asset drawdown.

In this paper we ask if the key features of the drawdown of home equity and personal retirement assets are reflected in the drawdown of other assets as well. Our key data source is the Health and Retirement Study (HRS). We use eight waves of data from the original HRS cohort who were age 51 to 61 in 1992 and seven waves of data from the original Asset and Health Dynamics Among 
the Oldest Old (AHEAD) cohort who were age 70 and older in 1993. The results are based on the observed evolution of the assets of these two cohorts as they age. The HRS cohort is followed from 1992 until 2006 and the AHEAD cohort from 1993 until 2006. Thus our results do not capture the effect of the recent sharp decline in financial and housing markets.

A key issue confounding our analysis is the high incidence of apparent asset reporting errors and missing data. Details of these data problems are set out in an appendix. We use medians and trimmed means in an attempt to limit the effects of data errors. We are also limited in our analysis because the HRS and AHEAD data do not allow reliable estimation of 401(k) assets, an increasingly important source of retirement saving. This limitation and measurement problems are discussed in section 1 below.

This paper is divided into eight sections. The first five consider the relationship between family status transitions and the post-retirement evolution of total assets, defined broadly to include financial assets, home equity and retirement plan assets. We emphasize the drawdown of assets that are controlled directly by the household. Thus we do not include the asset value of annuities received from Social Security or from defined benefit pension plans. We focus on how asset accumulation patterns vary across households that experience different family status transitions, distinguishing continuing twoperson families, families that transition from two-person to one-person families, and continuing one-person families. In section 1 we describe how the data are organized for analysis, as well as the limitations of the data. In section 2 we consider the evolution of the assets of the HRS cohort between 1992 and 2006. In section 3, we consider the evolution of the assets of the older AHEAD cohort between 1993 and 2006. In section 4, we look more closely at the assets of individuals in households that experience a family status transition by considering their assets before and after the transition. In section 5, we compare the results based on the HRS and AHEAD cohorts with results for the same cohorts based on the SIPP data. We also expand the analysis of family status transitions to consider the effect of latent health on the level and the evolution of assets. In section 6 we describe the latent health index that we use to index health status. In section 7, we describe the relationship between latent health and the level and evolution of assets, within family status transition groups. Section 8 is a summary and discussion of future work.

\section{Family Status Transitions and the Evolution of Assets: Data Limitations and Organization}

We begin with analysis of the evolution of total assets based on data from the HRS using both the original HRS cohort and the AHEAD cohort. The analysis, however, is confounded by data limitations and reporting errors that have motivated the analysis and conditioned how the analysis proceeds. Thus 
we give attention to these issues before explaining how the data is organized for analysis.

The key limitation of the HRS and AHEAD data is the measurement of 401(k) assets. These datasets provide reliable information on assets in IRA and Keogh plans but, as noted above, not on assets in $401(\mathrm{k})$ accounts. A large proportion of IRA balances (which are included in our measure of total assets) represent rollovers from $401(\mathrm{k})$ plans, however. But the information on directly held $401(\mathrm{k})$ balances in the HRS is incomplete and is not used in this analysis. Thus we compare the results based on the HRS and AHEAD data with results based on the SIPP that does include 401(k) assets. We find that SIPP trends are similar to those based on the HRS and AHEAD data, but the rates of increase are typically higher based on the SIPP data.

Data reporting errors and missing data also pose difficulties for our analysis and condition the approach we have taken. Curtin, Juster and Morgan (1989), Juster, Smith and Stafford (1999), and Bosworth and Smart (2009) and others have shown that survey estimates of wealth are well-known to be susceptible to under-reporting and misreporting. This is true in all large household-level surveys and is a particularly severe problem among wealthy respondents.

A careful examination of the HRS data used in this analysis reveals two sources of apparent error. The first is the misreporting of asset ownership. A household may, for example, report owning a home (or some other major asset) for four waves, then report no ownership for a wave, and then report ownership again in subsequent waves. ${ }^{1}$ The second source is the misreporting of the value of an asset. In this case a respondent may report a particular value for several periods, then report a wildly different value for one period, and then report the original value in subsequent periods. In some cases these apparent "errors" may be valid responses--a person may sell a home and not repurchase for another year. If this is the case, then the loss of value in the "misreported" asset should be offset by an increase in value elsewhere on the household balance sheet. This does not happen in the majority of the cases, so misreporting is the most likely explanation for many of the extreme dips and spikes we observe in the data. Smith (1995) provides additional details on inconsistent asset levels in the first two waves of the HRS.

The high frequency of apparent misreporting of asset values leads to volatile estimates of mean assets, especially in small samples. This type of

\footnotetext{
${ }^{1}$ This problem is particularly severe for pension assets - a major component of total wealth. Gustman and Steinmeier (2004), Gustman, Steinmeier and Tabatabai (2008) and, Dushi and Honig (2008) show that a large fraction of the population has little knowledge of the features of their pension and often misreport something as basic as pension type (DC vs DB). In many surveys, including the HRS, a misreported pension type means that the pension balance is not collected.
} 
measurement error is particularly serious in longitudinal analyses when the variable of interest is the wave-to-wave change in wealth. A single misreport in a panel will result in two incorrect measurements of the change in wealth. For example, failure to report an asset on one wave will lead to a large negative change and a large positive change in two consecutive surveys. Moreover, these spurious changes are likely to be large relative to correctly reported values, so misreports generate a large amount of "noise" relative to signal, thus making it very difficult to obtain reliable estimates of even simple statistics such as the mean rate of wealth accumulation.

We have directed considerable attention to dealing with data problems associated with apparent misreporting. In most instances we do not directly estimate changes in total assets. Instead we obtain estimates of the change in assets by separately estimating the level of assets at the beginning of the period and the level of assets at the end of the period and then calculating the mean change as the difference between mean levels. We also make extensive use of medians and trimmed means to lessen the influence of outliers that may be the result of misreporting. ${ }^{2}$

There are two additional features of the HRS data that bear on the quality of reported asset information. First, these apparent misreporting errors persist in the data despite the sophisticated bracketing methods employed in the HRS. When a respondent fails to provide an asset value, a follow-up question asks if the value fell in a particular interval. Additional follow-up questions narrow the range. These bracketing methods have been shown to significantly reduce the rate of non-response. Second, there are some special issues concerning the collection of data on 401(k) assets. In particular, persons are well-known to misreport the type of pension (defined benefit or defined contribution) they have. When a currently employed person with a DC plan misreports his pension as DB, the person is not queried about the balance. Thus we observe many large waveto-wave fluctuations in $401(\mathrm{k})$ assets that appear to be the result of misreporting pension type. There are also difficulties with the collection of $401(\mathrm{k})$ balances for persons who are retired, but still have a 401(k) balance with their previous employer. In principal, information about pensions with past employers should have been "pre-loaded" in the HRS survey instruments to prompt questions about these balances. However, in many years this pre-loading did not occur or was incomplete so complete 401(k) balances were not obtained. Because of these problems we have chosen to exclude all 401(k) balances from the measure of total assets in our analyses using the HRS (we do include IRA and Keogh

\footnotetext{
${ }^{2}$ There is, in principle, another approach we could employ--go back to the raw data and "correct" misreported values. This approach would rely in part on an "asset verification" module, described in Hill (2006) that is now part of the bi-annual HRS survey. Responses in the current survey wave are compared to responses in the previous wave and respondents are asked to reconcile inconsistencies. The data collected by this module have not been used in the present analysis, although we hope to use them in future analyses.
} 
assets). In section 5 we compare HRS data to SIPP data, which contains more complete $401(\mathrm{k})$ data, to gauge the extent of this problem.

Our analysis uses wealth at the beginning and end of each two-year interval to calculate the change in assets. This change in assets can be separated into two components: withdrawals (or deposits) and capital losses (gains). The distinction is particularly relevant in the current financial crisis because it is important to know if declining wealth reflects active asset spenddown or passive asset repricing. The HRS provides limited information on this distinction. There is very good information on direct withdrawals from IRAs and Keoghs, but the data on withdrawals from 401(k) are subject to the same problems that prevent us from using the data on $401(\mathrm{k})$ balances. There is also very good data on house sales that allow us to distinguish between withdrawals of home equity and falling house values. The data on withdrawals from other asset balances is less complete. Respondents are only asked if they bought or put money in stocks or mutual funds and if they sold or cashed in any stocks or mutual funds since the previous interview. They are also asked the dollar amount of these transactions. There is no information on withdrawal of funds from other assets (e.g. bonds, CDs, money market instruments, etc.) held by households.

We turn now to how we organize the data for analysis. For this analysis the unit of observation is the person rather than the household. From the HRS we follow persons first surveyed in 1992 when they were age 51 to 61 and subsequently resurveyed every other year through 2006 (when they were age 65 to 75). We look at asset growth over the two-year intervals between each of the seven survey waves, from 1992 to 1994, 1994 to 1996 and so forth through 2004 to 2006. From the AHEAD cohort, we follow persons aged 70 to 80 first surveyed in 1993 and then resurveyed in 1995, 1998, 2000, 2002, 2004, and 2006. For these persons we consider changes from 1993 to 1995, 1995 to 1998, 1998 to 2000, 2000 to 2002, 2002 to 2004, and 2004 to 2006. In many instances we follow subsets of the HRS and AHEAD age ranges, for example looking only at persons age 56 to 61 from the HRS or persons age 70 to 75 from the AHEAD. The age groups we consider are summarized in Figure 1-1. For each age interval the figure shows the range of ages for the youngest members of the group and for the oldest member of the group. For example, the last row of the figure, labeled "HRS 51-55 in 1992: youngest" shows that the youngest member of this age interval was 51 years old when first surveyed in 1992 and 65 years old when last surveyed in 2006. 


\section{Figure 1-1. HRS and AHEAD cohorts and age groups followed}

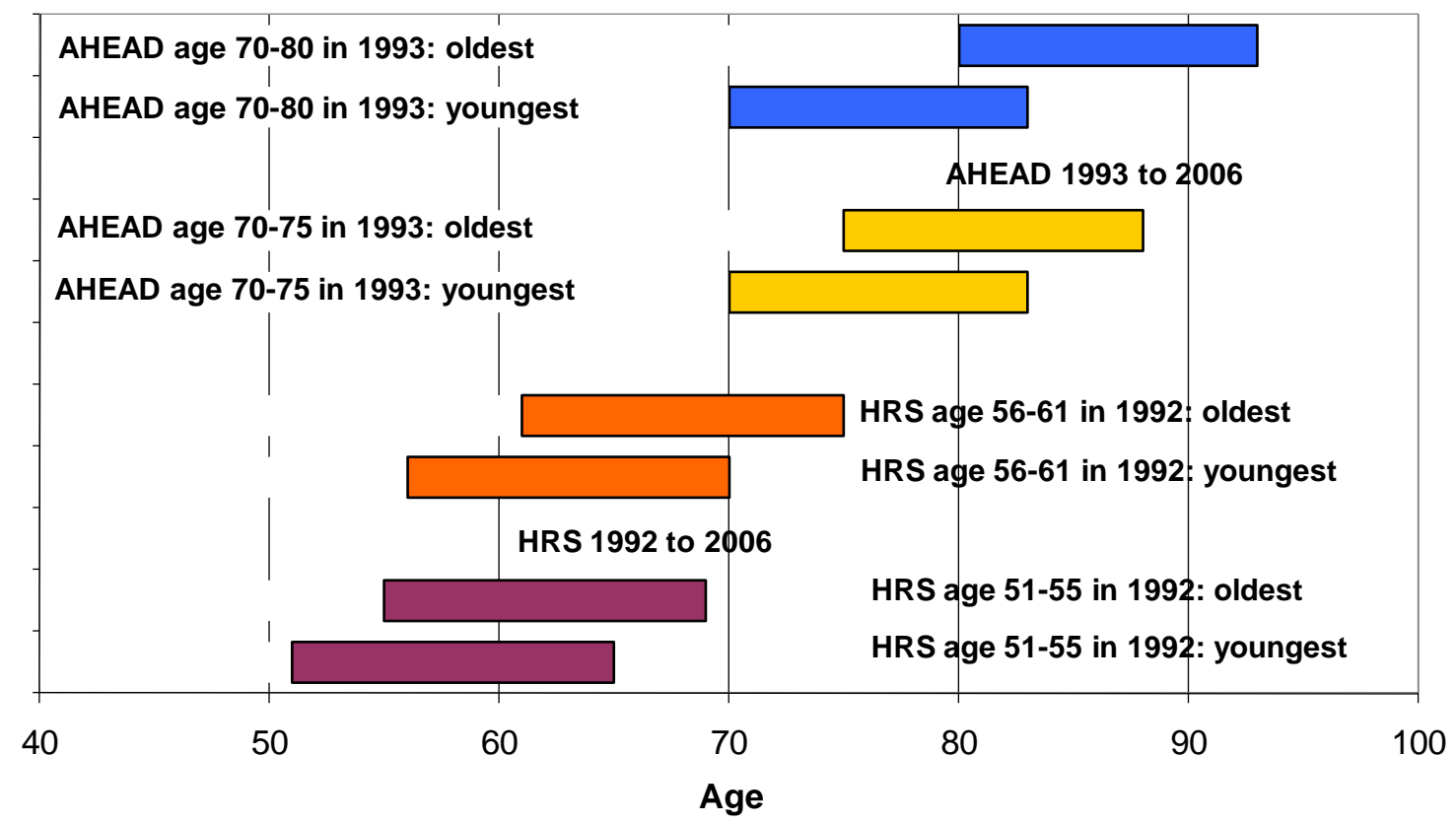

Finally we also use data from three panels of the SIPP. From the 1996 panel of the SIPP we obtain data for 1997, 1998, 1999 and 2000 and thus we calculate asset changes from 1997 to 1998, 1998 to 1999, and 1999 to 2000. From the 2001 panel of the SIPP we have data for 2001, 2002, and 2003, and thus changes from 2001 to 2002, 2002 to 2003, and 2003 to 2004. From the 2004 panel of SIPP we have data for 2004 and 2005, and thus the change from 2004 to 2005. We have six year-to-year changes from the SIPP data, from 1997 to 1998, 1998 to 1999, and so forth to 2004 to 2005. The SIPP data differ in one important way from the HRS data: SIPP collects data for all respondents age 15 and older (but top-codes age at 85). Thus it is possible to choose a sample from the SIPP that "matches" as closely as possible the age ranges in the two HRS samples.

For each of the three data sources we consider assets at the beginning and end of each interval, although the width of the intervals differ-one year in the SIPP and, with one exception, two years in the HRS and the AHEAD data. For each person in each survey we categorize family status at the beginning of the interval as belonging to either a one-person household or to a two-person household. Over the interval between surveys a person initially in a one-person household may remain in a one-person household. We designate the family status transition for this person as $1 \rightarrow 1$ indicating that the person is in a oneperson household in both years. If this person remarried (or partnered) during the two year interval then the person is classified as $1 \rightarrow 2$. Similarly, we classify persons initially in two-person households as $2 \rightarrow 2$ if the person remains in a twoperson household, $2 \rightarrow 1$ (div) if the person divorces or separates by the end of the 
interval and $2 \rightarrow 1$ (wid) if the spouse dies by the end of the interval. The sample sizes for persons classified as $1 \rightarrow 2$ are quite small so this group has been excluded from many of the figures presented below.

To illustrate this organization of the data, we show HRS assets by family status in both 1992 and 1994, and the change in assets between the two years. Table 1-1 shows these data for persons aged 51 to 61 in 1992 (in year 2000 dollars). Total assets include equity in owner-occupied housing, IRA and Keogh balances, other financial assets, and the value of vehicles, less debt. The value of business assets and other real estate are excluded. Balances in 401(k) plans are excluded from the HRS and the AHEAD data because, as noted above, a complete $401(k)$ series cannot be obtained from these sources, but $401(k)$ assets are included in the SIPP data. We present medians and trimmed means, as well as simple means, because the latter are sensitive to outliers.

The table shows the organization of one of many family status transitions that can be obtained from the HRS, AHEAD, and SIPP surveys. Between 1992 and 1994 the median wealth of persons in continuing two-person households increased 10.9 percent and the median wealth of persons in continuing oneperson households increased 7.6 percent. Among persons experiencing a change in family status, persons becoming widowed experienced a slight increase in assets, those becoming divorced experienced a large decline, and persons marrying saw their assets increase dramatically. The means in the lower panel show a similar pattern. The key results we present in later sections are based on graphical descriptions of the changes by family status for each of the intervals and for each of the data sources. As emphasized above, reporting errors can have an important effect on the changes between the beginning and the end of an interval. To mitigate the effect of errors on the results shown in this paper we emphasize comparisons based on trimmed means and on medians, as explained above. 


\begin{tabular}{|c|c|c|c|c|}
\hline \multicolumn{5}{|c|}{$\begin{array}{l}\text { Table1-1. Median and mean total assets in } 1992 \text { a } \\
1994 \text { for HRS respondents age } 51 \text { to } 61 \text { in } 1992 \text { by } \\
\text { family status }\end{array}$} \\
\hline $\begin{array}{l}\text { family } \\
\text { status } \\
\text { transition } \\
\text { group }\end{array}$ & $\begin{array}{l}\text { total assets } \\
\text { in } 1992\end{array}$ & $\begin{array}{l}\text { otal assets } \\
\text { in } 1994\end{array}$ & change & $\begin{array}{l}\text { percent } \\
\text { change }\end{array}$ \\
\hline \multicolumn{5}{|c|}{ Medians } \\
\hline $2 \rightarrow 2$ & 142,263 & 157,723 & 15,460 & 10.9 \\
\hline $2 \rightarrow 1$ (wid) & 83,395 & 72,019 & $-11,376$ & -13.6 \\
\hline $2 \rightarrow 1$ (div) & 95,414 & 40,010 & $-55,404$ & -58.1 \\
\hline $1 \rightarrow 2$ & 75,301 & 113,593 & 38,292 & 50.9 \\
\hline $1 \rightarrow 1$ & 39,239 & 42,214 & 2,975 & 7.6 \\
\hline \multicolumn{5}{|c|}{ Means } \\
\hline $2 \rightarrow 2$ & 228,693 & 255,843 & 27,150 & 11.9 \\
\hline $2 \rightarrow 1$ (wid) & 173,759 & 154,696 & $-19,063$ & -11.0 \\
\hline $2 \rightarrow 1$ (div) & 165,988 & 114,748 & $-51,240$ & -30.9 \\
\hline $1 \rightarrow 2$ & 135,573 & 194,098 & 58,525 & 43.2 \\
\hline $1 \rightarrow 1$ & 99,799 & 111,079 & 11,280 & 11.3 \\
\hline
\end{tabular}

Before looking at additional results, we show sample sizes for each interval by family status transition in Table 1-2. These data draw attention to the effect of selection on the change in assets within and between intervals. For example, consider the change in assets of persons in continuing two-person households $(2 \rightarrow 2)$ in the 1992-1994 interval, which is used to obtain the estimates in the first row of Table 1-1. In subsequent sections we report changes in assets for these persons in later intervals as well. These persons will only appear in the $2 \rightarrow 2$ transition group for the next interval, 1994-1996, if they remain in a two-person household for the next two years. Those who will lose a spouse during the next two years will be in the $2 \rightarrow 1$ group in 1994-1996. Persons who will lose a spouse in a subsequent interval tend to have lower assets than those who will continue in two-person households. The numbers in the Table 1-2 only give a general indication of the extent of selection. For example, consider the decline in the number of persons in the $2 \rightarrow 2$ group in the HRS sample between the1992-1994 and the 1994-1996 intervals $(6,365$ to 5,732). Part of the decline in the number of persons occurs because some of the persons in the $2 \rightarrow 2$ group in 1992-1994 are in one of the $2 \rightarrow 1$ groups in 1994-1996. This is the key selection. Persons in the $2 \rightarrow 1$ group have lower assets than persons in the $2 \rightarrow 2$ group. But part of the decline in the number of persons is also due to attrition 
from the sample. In addition, persons in the $1 \rightarrow 2$ group in 1992-1994 are in the $2 \rightarrow 2$ group in 1994-1996 if they remain married for the next two years. Persons who continue in the $1 \rightarrow 1$ group also tend to have greater assets than those who leave the sample because of death.

\begin{tabular}{|c|c|c|c|c|c|c|c|}
\hline \multicolumn{8}{|c|}{ HRS persons age 51 to 61 in 1992} \\
\hline group & 1992-1994 & 1994-1996 & 1996-1998 & $1998-2000$ & $2000-2002$ & $2002-2004$ & 2004-2006 \\
\hline $2 \rightarrow 2$ & 6,365 & 5,732 & 5,344 & 4,978 & 4,614 & 4,382 & 4,017 \\
\hline $2 \rightarrow 1$ (wid) & 108 & 111 & 133 & 131 & 127 & 118 & 153 \\
\hline $2 \rightarrow 1$ (div) & 121 & 69 & 64 & 41 & 38 & 32 & 40 \\
\hline $1 \rightarrow 2$ & 88 & 96 & 71 & 65 & 58 & 65 & 44 \\
\hline $1 \rightarrow 1$ & 1,598 & 1,559 & 1,535 & 1,554 & 1,554 & 1,630 & 1,634 \\
\hline Total & 8,280 & 7,567 & 7,147 & 6,769 & 6,391 & 6,227 & 5,888 \\
\hline \multicolumn{8}{|c|}{ AHEAD persons age 70 to 80 in 1993} \\
\hline type & & 1993-1995 & 1995-1998 & $1998-2000$ & $2000-2002$ & $2002-2004$ & 2004-2006 \\
\hline $2 \rightarrow 2$ & & 2,371 & 1,813 & 1,412 & 1,043 & 771 & 551 \\
\hline $2 \rightarrow 1$ (wid) & & 187 & 213 & 181 & 142 & 118 & 86 \\
\hline $2 \rightarrow 1$ (div) & & 7 & 19 & 7 & 4 & 3 & \\
\hline $1 \rightarrow 2$ & & 29 & 29 & 13 & 15 & 12 & 10 \\
\hline $1 \rightarrow 1$ & & 1,778 & 1,613 & 1,601 & 1,468 & 1,318 & 1,138 \\
\hline Total & & 4,372 & 3,687 & 3,214 & 2,672 & 2,222 & 1,785 \\
\hline
\end{tabular}

\section{The HRS Cohort}

We next summarize asset changes for the HRS cohort and then for the AHEAD cohort; we also compare the two and compare results based on these surveys with results based on the SIPP. We begin by graphing the "raw" means like those presented in the bottom panel of Table 1-1. As the graphs will show, the data are confounded by a large number of reporting errors and missing values. Ultimately, we will need to find a way to "correct" the errors and "fill in" the missing values. For present purposes, we simply show how two alternative estimation procedures-trimming outliers and using medians-can affect the results. To demonstrate the effect of alternative estimation procedures we use data for persons aged 51 to 55 in 1992 from the HRS cohort.

Figure 2-1 shows the means based on the raw data. Here and in the subsequent analysis all values are in constant year 2000 dollars. These estimates are analogous to those shown in the bottom panel of Table 1-1. There appear to be many aberrant within and between interval changes in assets. Closer examination of the data reveals that there are a large number of apparent 
errors in the raw data. These include cases where balances for major assets (such as housing or retirement accounts) are apparently misreported (the asset total reported in one wave is very different from the total reported in adjacent waves). The effect of outliers is evident in the figure. To address this problem, we show means based on trimmed data in Figure 2-2. and estimates of medians in Figure 2-3.

To obtain the trimmed means we estimate separate GLS regressions for assets at the beginning and end of each interval. Each GLS regression allows the residual variance to differ from interval to interval. For each family status transition group, we estimate a specification of this form:

$$
\begin{aligned}
& A_{i b j}=\alpha_{b}+\sum_{j=1}^{J} \delta_{b j} I_{j}+\varepsilon_{i b j} \\
& A_{i e j}=\alpha_{e}+\sum_{j=1}^{J} \delta_{e j} I_{j}+\varepsilon_{i e j}
\end{aligned}
$$

In these equations $A$ is the asset level (in constant dollars). The first equation pertains to beginning assets in each interval and the second equation to ending assets; $I_{j}$ is an indicator variable for the $j$ th interval, $i$ indicates person, $b$ indicates the beginning of an interval, and e indicates the end of an interval. As set out, these equations reproduce exactly the results shown in Figure 1-1. The key feature of the estimates is that the error variance is allowed to vary by interval. To obtain trimmed means, for each interval and for each family status group we eliminated the observations with the top one percent and the bottom one percent of residuals. In cases where there are fewer that 100 observations in an interval we exclude the observations with the highest and lowest residuals.

Then we re-estimate the same GLS regressions on the trimmed data and predict the mean beginning and ending assets that are graphed in Figure 2-2. For illustration, Appendix Table 2-1 shows the GLS estimates for beginning assets of $2 \rightarrow 2$ persons based on the raw data and then based on the trimmed data. It can be seen that the standard error of the means based on the trimmed data are for some intervals as little as one-third as large as the standard error based on the raw data. The comparisons are similar for the other transition groups.

Comparing Figures 2-1 and 2-2 suggests that trimming reduces the estimated mean assets, especially for the $2 \rightarrow 2$ and $1 \rightarrow 1$ transitions. For example, the 2006 mean for the $2 \rightarrow 2$ group is reduced from over $\$ 600,000$ using the raw data to just over $\$ 400,000$. In addition, the within-interval changes are much more consistent from one interval to the next. Some apparently aberrant means for the $2 \rightarrow 1$ (widowed) and $2 \rightarrow 1$ (divorced) groups remain. 
We also experimented with trimmed data based on the change in assets over each interval. In this case, we estimated a GLS regression like the one above but used the change in assets for each interval (instead of one regression for beginning assets and a second for ending assets) as the dependent variable. Then for each interval, the top and bottom one percent of changes were eliminated. In most instances, we report only the trimmed results based on asset levels, but in a few instances we have calculated average asset changes over all intervals based on trimmed change data.

Figure 2-3 shows medians. The medians are much lower than the means, as might be expected, and the apparently aberrant mean values are not reproduced in the medians. For the other age groups and cohorts discussed below only trimmed mean and median values are shown.

Focusing on the trimmed mean results in Figure 2-2, several general features of the data stand out. First the assets of persons in continuing twoperson households $(2 \rightarrow 2)$ increase in each interval (all in year 2000 dollars). Second the assets of continuing $1 \rightarrow 1$ persons in the $1 \rightarrow 1$ group also increase in most intervals; 2000-2002 is the only exception. Third, the assets of $1 \rightarrow 1$ families are much lower than the assets of $2 \rightarrow 2$ families in all intervals.

Fourth, the assets of persons in two-person households that will become one-person households during the interval $(2 \rightarrow 1)$ are typically much lower at the beginning of an interval than the assets of persons in continuing two-person households $(2 \rightarrow 2)$. And, the assets of $2 \rightarrow 1$ (divorced) persons typically decline substantially within each interval. The asset of $2 \rightarrow 1$ (widowed) persons--although also much lower than the assets of $2 \rightarrow 2$ persons at the beginning of the perioddo not decline in most intervals. The medians in Figure 2-3 show much the same pattern. 
Figure 2-1. Mean total assets for HRS persons age 51 to 55 in 1992

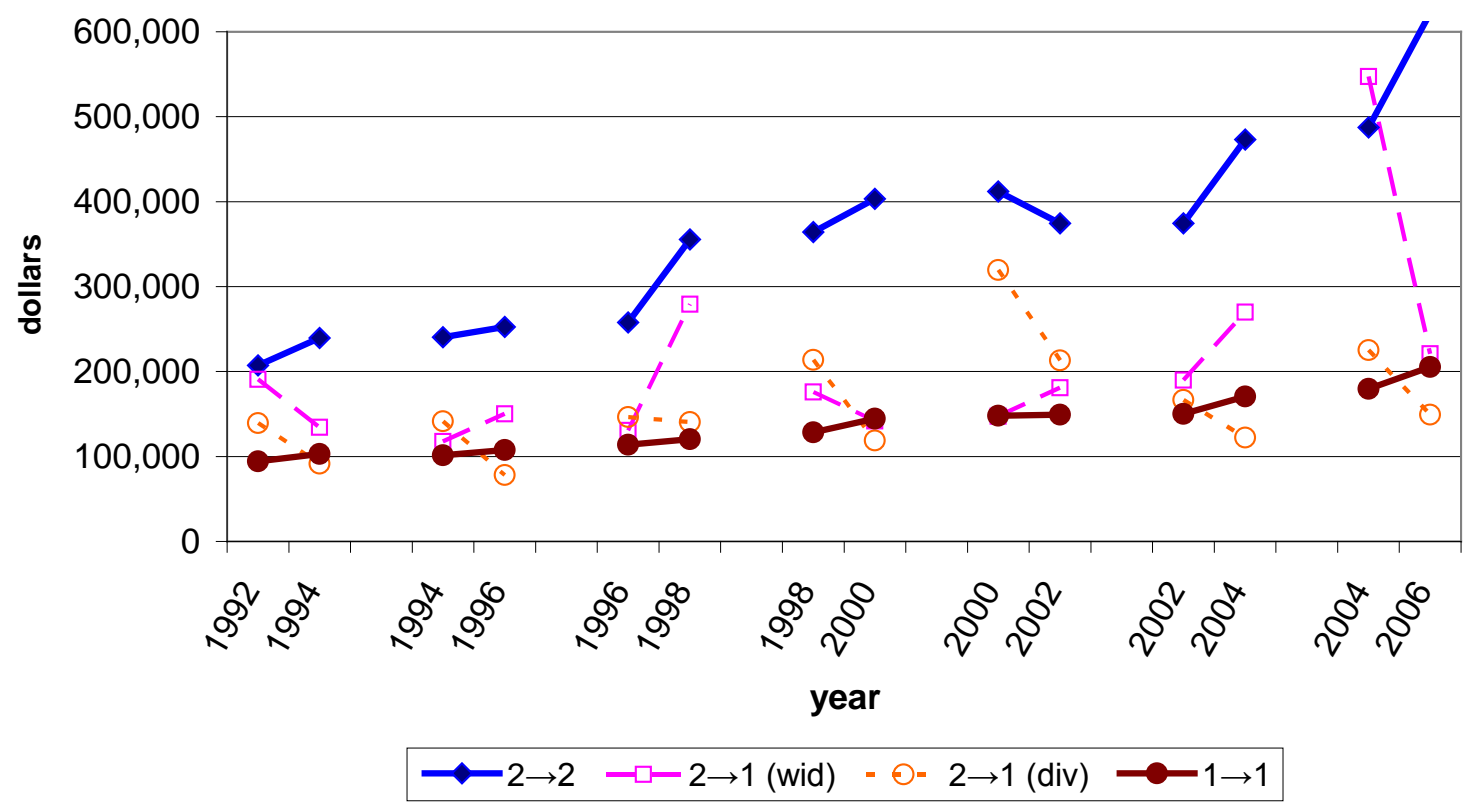

Figure 2-2. Mean total assets for HRS persons age 51 to 55 in 1992, trimmed

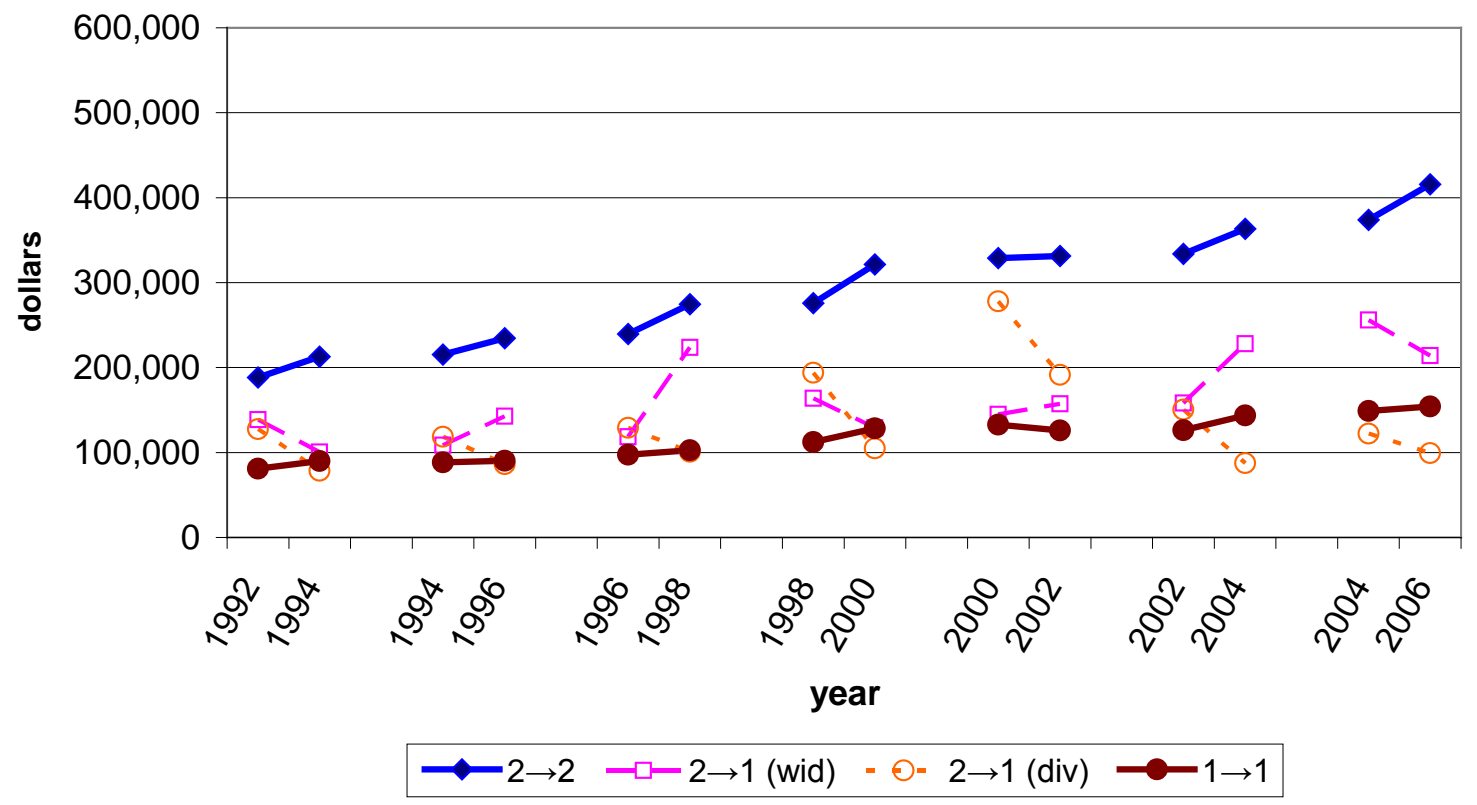




\section{Figure 2-3. Median total assets for HRS persons age 51 to 55 in 1992}

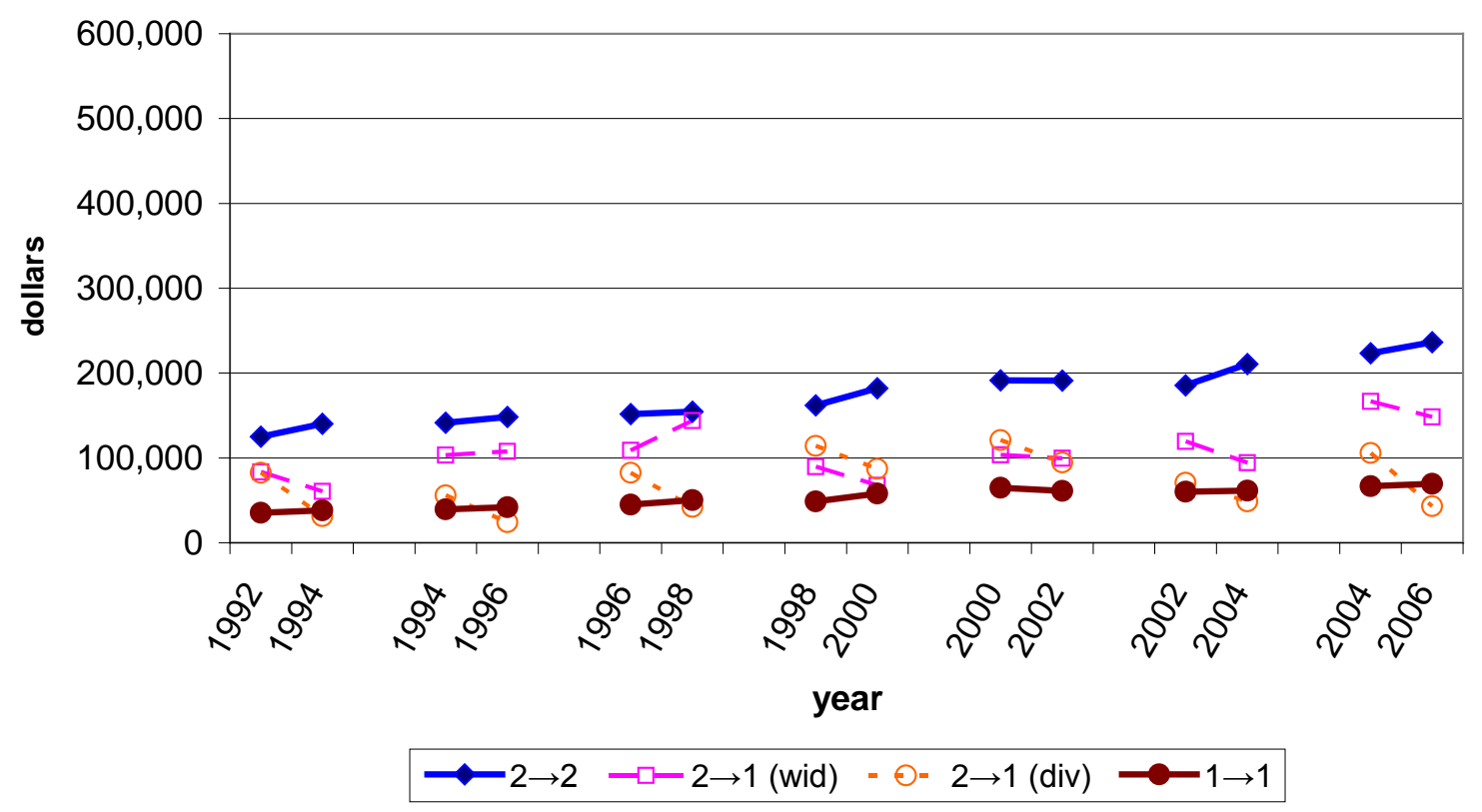

The average change in assets in each interval is summarized in Table 2-1 for each of the four family status transition groups and for each of the three estimation procedures. The average increase over the seven intervals is shown in the second column. Recall that beginning assets in each interval differ substantially by family status transition group. To quantify the difference, the first column of this table shows the average (over the seven intervals) of the ratio of the beginning assets of the $2 \rightarrow 1$ and $1 \rightarrow 1$ groups relative to the beginning assets or the $2 \rightarrow 2$ group. For example, based on trimmed means the beginning assets of the $2 \rightarrow 1$ (widowed) transition groups was about 56 percent of the average of the $2 \rightarrow 2$ group; the average of the $2 \rightarrow 1$ (divorced) group is about 59 percent of the $2 \rightarrow 2$ group. Asset changes (in the second column) show that the assets of the $2 \rightarrow 2$ group increase on average by close to 11 percent but the average of the $2 \rightarrow 1$ (divorced) group fell by about 32 percent based on the trimmed means. The average of the $2 \rightarrow 1$ (widowed) group increased by about 15 percent. The beginning assets of the $1 \rightarrow 1$ group were only about 40 percent of the assets of the $2 \rightarrow 2$ group. The mean assets of the $1 \rightarrow 1$ persons increased by about 6.5 percent, a little more than half the rate of increase observed for the $2 \rightarrow 2$ group.

The medians show somewhat different magnitudes but broadly similar patterns for the most part. The medians show that the beginning assets of the $2 \rightarrow 1$ (widowed) persons were about 66 percent of $2 \rightarrow 2$ persons, the assets of $2 \rightarrow 1$ (divorced) persons about 54 percent of the assets of the $2 \rightarrow 2$ persons, and the assets of $1 \rightarrow 1$ persons only about 30 percent of those of the $2 \rightarrow 2$ persons. 
The median increase in the assets of $2 \rightarrow 2$ persons was about 5 percents. But the median increase in the assets of the $1 \rightarrow 1$ group was only about 0.04 percent. The median decline in the assets of $2 \rightarrow 1$ (divorced) persons was about 27 percent and the median of the assets of $2 \rightarrow 1$ (widowed) persons was about 1 percent.

\begin{tabular}{|c|c|c|}
\hline Group & $\begin{array}{l}\text { Average of } \\
\text { beginning assets } \\
\text { relative to } 2 \rightarrow 2\end{array}$ & $\begin{array}{l}\text { Average } \% \\
\text { increase over } 7 \\
\text { intervals* }\end{array}$ \\
\hline & \multicolumn{2}{|c|}{ Means } \\
\hline $2 \rightarrow 2$ & 1.000 & $14.42 \%$ \\
\hline $2 \rightarrow 1$ (wid) & 0.544 & $26.17 \%$ \\
\hline $2 \rightarrow 1$ (div) & 0.606 & $-31.23 \%$ \\
\hline \multirow[t]{2}{*}{$1 \rightarrow 1$} & 0.405 & $8.02 \%$ \\
\hline & \multicolumn{2}{|c|}{ Trimmed means } \\
\hline $2 \rightarrow 2$ & 1.000 & $10.57 \%$ \\
\hline $2 \rightarrow 1$ (wid) & 0.561 & $15.42 \%$ \\
\hline $2 \rightarrow 1$ (div) & 0.585 & $-32.18 \%$ \\
\hline $1 \rightarrow 1$ & 0.405 & $6.45 \%$ \\
\hline & \multicolumn{2}{|c|}{ Medians } \\
\hline $2 \rightarrow 2$ & 1.000 & $4.99 \%$ \\
\hline $2 \rightarrow 1$ (wid) & 0.657 & $0.90 \%$ \\
\hline $2 \rightarrow 1$ (div) & 0.541 & $-27.03 \%$ \\
\hline $1 \rightarrow 1$ & 0.303 & $0.43 \%$ \\
\hline \multicolumn{3}{|c|}{$\begin{array}{l}\text { *Note: For the trimmed means this is the difference between } \\
\text { beginning mean and ending mean assets, as a percent of beginning } \\
\text { mean assets, averaged over the seven intervals. For medians this is } \\
\text { the median change in assets within an interval as a percent of mediar } \\
\text { beginning assets, averaged over the seven intervals. }\end{array}$} \\
\hline
\end{tabular}

In this section we have presented estimates separately for each family

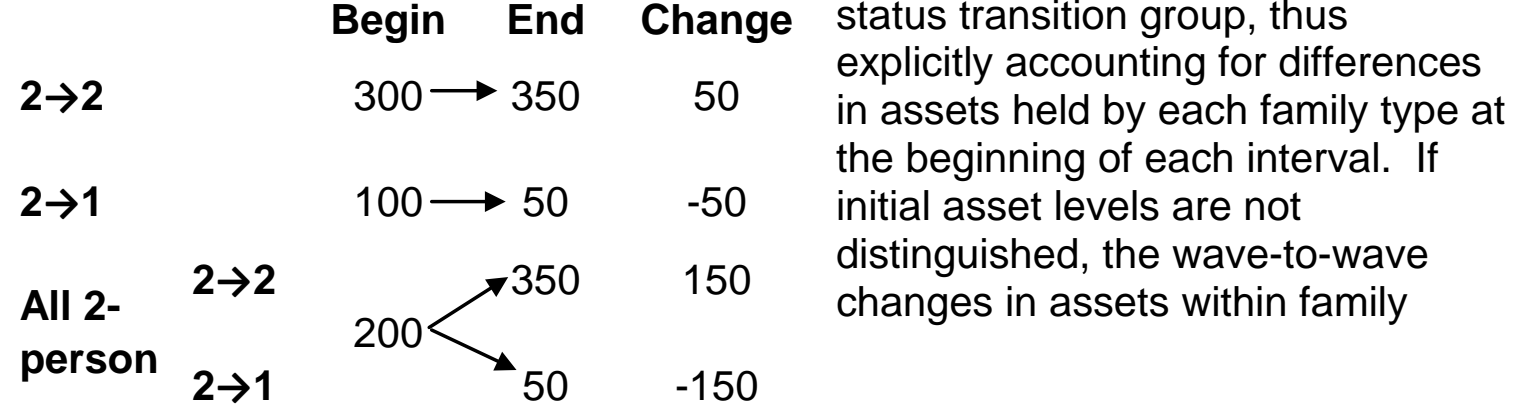


status transition groups are confounded with differences in initial asset levels. This is illustrated in the adjacent diagram which shows beginning and ending assets for hypothetical $2 \rightarrow 2$ and $2 \rightarrow 1$ groups of equal size (in hundreds of thousands of dollars). The first row shows that assets for the $2 \rightarrow 2$ group increase by 50 (from 300 to 350). The next row shows that assets for the $2 \rightarrow 1$ group decline by 50 (from 100 to 50). If we do not distinguish the two groups and begin with the average of the assets of the two groups, we overestimate the asset increase for the $2 \rightarrow 2$ families and overestimate the asset decrease for the $2 \rightarrow 1$ families as shown in the bottom two rows of the diagram.

Figures 2-4 and 2-5 and Table 2-2 pertain to HRS persons aged 56 to 61 in 1992. The key difference between this age cohort and the 51 to 55 cohort is that the younger cohort would have been in the labor force for many of the intervals; they were between the ages of 65 to 69 in 2006 and on average retired in about 2000 or 2002. The older age cohort would have been 70 to 75 in 2006 and on average may have retired in about 1996.

\section{Figure 2-4. Mean total assets for HRS persons age 56 to 61 in 1992, trimmed}

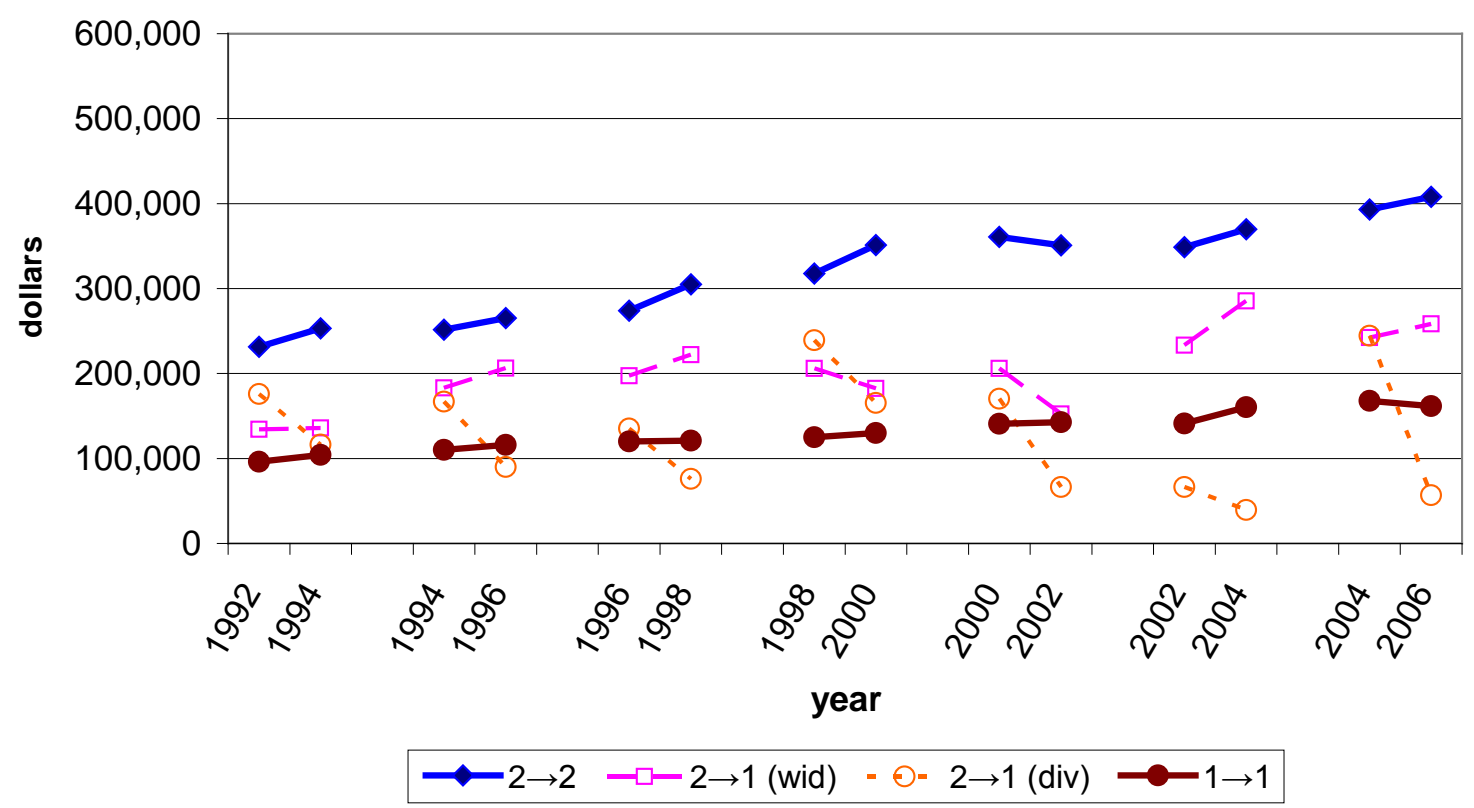




\section{Figure 2-5. Median total assets for HRS persons age 56 to 61 in 1992}

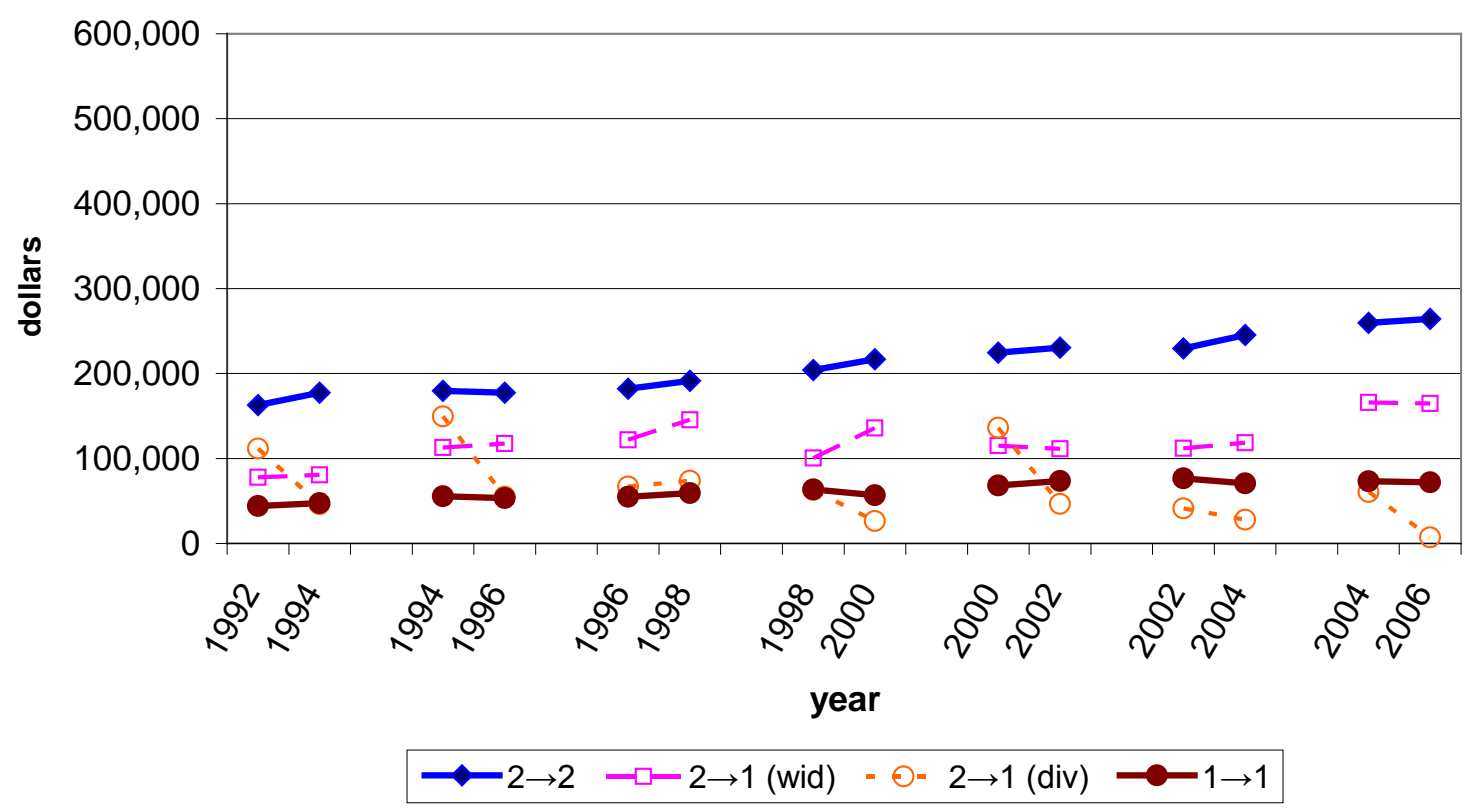

The general trends for the four transition groups for the 56 to 61 cohort are much the same as the trends for the 51 to 55 cohort. There are differences in magnitude, however, and they can best be seen by comparing the averages for the two age cohorts shown in Table 2-2. Based on the trimmed means, the average within-interval percent increase in assets is lower for the older $2 \rightarrow 2$ and $1 \rightarrow 1$ persons $-6.3 \%$ versus $10.6 \%$ and $4.2 \%$ versus $6.5 \%$ for the $2 \rightarrow 2$ and the $1 \rightarrow 1$ groups respectively. The large reduction in the assets of the $2 \rightarrow 1$ (divorced) group is evident for both age cohorts. Based on medians, the increases are close to zero for both the younger and the older age cohorts. Indeed for the older cohort the change in the median assets of the $1 \rightarrow 1$ group is zero. The large decline in the assets of the $2 \rightarrow 1$ (divorced) group is again evident.

It might be expected that the increase in the assets of the younger group would be greater since they were in the labor force for more years than the older group and thus could save out of earning for more years. 


\begin{tabular}{|c|c|c|c|c|}
\hline \multirow[b]{2}{*}{$\begin{array}{l}\text { Family status } \\
\text { transition group }\end{array}$} & \multicolumn{2}{|c|}{ Age 51-55 } & \multicolumn{2}{|c|}{ Age 56-61 } \\
\hline & $\begin{array}{l}\text { Average of } \\
\text { beginning } \\
\text { assets } \\
\text { relative to } \\
2 \rightarrow 2\end{array}$ & $\begin{array}{c}\text { Average } \\
\% \\
\text { increase } \\
\text { over } 7 \\
\text { intervals* }\end{array}$ & $\begin{array}{l}\text { Average of } \\
\text { beginning } \\
\text { assets } \\
\text { relative to } \\
2 \rightarrow 2\end{array}$ & $\begin{array}{c}\text { Average } \\
\% \\
\text { increase } \\
\text { over } 7 \\
\text { intervals* }\end{array}$ \\
\hline & \multicolumn{4}{|c|}{ Means } \\
\hline $2 \rightarrow 2$ & 1.000 & $14.4 \%$ & 1.000 & $8.6 \%$ \\
\hline $2 \rightarrow 1$ (widow) & 0.544 & $26.2 \%$ & 0.654 & $1.9 \%$ \\
\hline $2 \rightarrow 1$ (divorce) & 0.606 & $-31.2 \%$ & 0.656 & $-35.3 \%$ \\
\hline \multirow[t]{2}{*}{$1 \rightarrow 1$} & 0.405 & $8.0 \%$ & 0.413 & $4.8 \%$ \\
\hline & \multicolumn{4}{|c|}{ Trimmed means } \\
\hline $2 \rightarrow 2$ & 1.000 & $10.6 \%$ & 1.000 & $6.3 \%$ \\
\hline $2 \rightarrow 1$ (widow) & 0.561 & $15.4 \%$ & 0.648 & $2.5 \%$ \\
\hline $2 \rightarrow 1$ (divorce) & 0.585 & $-32.2 \%$ & 0.565 & $-47.6 \%$ \\
\hline \multirow[t]{2}{*}{$1 \rightarrow 1$} & 0.405 & $6.5 \%$ & 0.415 & $4.2 \%$ \\
\hline & \multicolumn{4}{|c|}{ Medians } \\
\hline $2 \rightarrow 2$ & 1.000 & $5.0 \%$ & 1.000 & $2.5 \%$ \\
\hline $2 \rightarrow 1$ (widow) & 0.657 & $0.9 \%$ & 0.558 & $2.6 \%$ \\
\hline $2 \rightarrow 1$ (divorce) & 0.541 & $-27.0 \%$ & 0.459 & $-22.6 \%$ \\
\hline $1 \rightarrow 1$ & 0.303 & $0.4 \%$ & 0.302 & $0.0 \%$ \\
\hline $\begin{array}{l}{ }^{*} \text { Note: For the trimm } \\
\text { and ending mean as } \\
\text { over the seven interv } \\
\text { an interval as a perc } \\
\text { intervals. averaged o }\end{array}$ & $\begin{array}{l}\text { ned means this i } \\
\text { sets, as a perce } \\
\text { vals. For mediar } \\
\text { ent of median b } \\
\text { ver the seven int }\end{array}$ & $\begin{array}{l}\text { is the differen } \\
\text { ent of beginnir } \\
\text { ins this is the r } \\
\text { beginning asse } \\
\text { tervals. }\end{array}$ & $\begin{array}{l}\text { between begin } \\
\text { mean assets, a } \\
\text { edian change in } \\
\text {, averaged over }\end{array}$ & $\begin{array}{l}\text { ing mean } \\
\text { veraged } \\
\text { assets within } \\
\text { the seven }\end{array}$ \\
\hline
\end{tabular}

\section{The AHEAD Cohort}

We now turn to the evolution of the assets of the older AHEAD cohort. This members of this cohort were aged 70 and over in 1993, when the survey began. They have been followed for six waves until 2006, when they were at least 83 years old. Figure 3-1 shows the trimmed mean assets of the respondents aged 70 to 80 in 1993, based on within-interval data that has been trimmed as described in the previous section. Results based on medians are shown in Figure 3-2. Rohwedder, Haider, and Hurd (2006) make a compelling case that the increase in assets between 1993 and 1995 is likely exaggerated because of under-reporting in the 1993 survey. For completeness, however, we show results for this interval as well as the other intervals. 
Figure 3-1. Mean total assets for AHEAD persons age 70 to 80 in 1993, trimmed

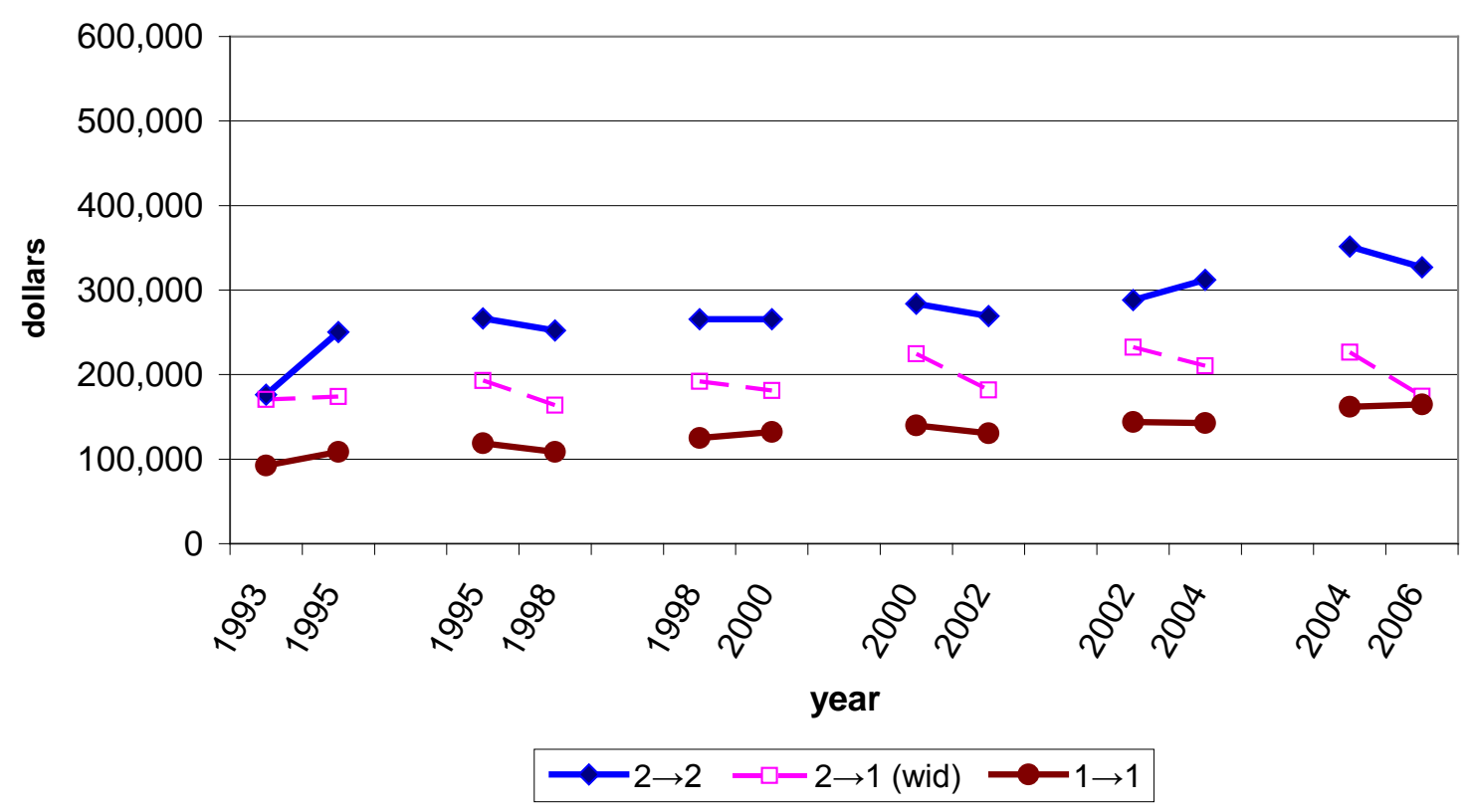

Figure 3-2. Median total assets for AHEAD persons age 70 to 80 in 1993

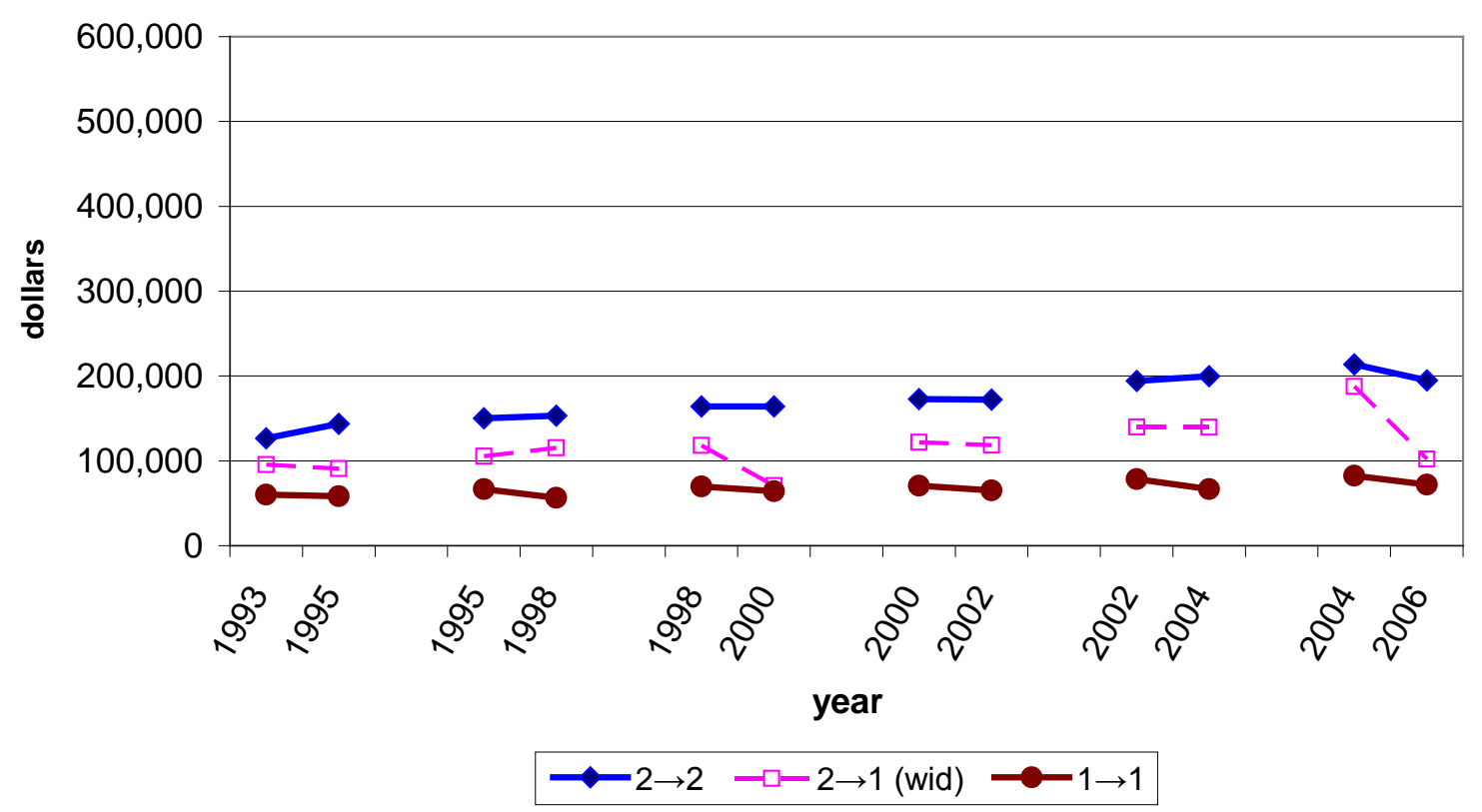

Results for both estimation procedures, as well as estimates based on the raw data, are summarized in Table 3-1. There are very few divorces in this age 
group so data are shown only for the $2 \rightarrow 1$ (widowed) group. Even in this age group, the assets of the $2 \rightarrow 2$ transition group increase on average by over 5 percent based on the trimmed means. The assets of the $1 \rightarrow 1$ group increase by about 1.5 percent based on the trimmed means. The assets of persons whose partners die decline by almost 11 percent, and the assets of persons who will become widowed in an interval are over 20 percent lower at the beginning of the interval than the assets of the continuing $2 \rightarrow 2$ transition group. The median increase in assets of the $2 \rightarrow 2$ group is less than 2 percent and the median change in the assets of the $1 \rightarrow 1$ group is negative (-0.59 percent).

\begin{tabular}{|c|c|c|}
\hline \multirow[t]{2}{*}{ Group } & $\begin{array}{c}\text { Average of } \\
\text { beginning assets } \\
\text { relative to } 2 \rightarrow 2\end{array}$ & $\begin{array}{c}\text { Average } \% \\
\text { increase over } 7 \\
\text { intervals* }\end{array}$ \\
\hline & \multicolumn{2}{|c|}{ Means } \\
\hline $2 \rightarrow 2$ & 1.000 & $7.10 \%$ \\
\hline $2 \rightarrow 1$ (widow) & 0.829 & $-18.22 \%$ \\
\hline \multicolumn{3}{|l|}{$2 \rightarrow 1$ (divorce) } \\
\hline \multirow[t]{2}{*}{$1 \rightarrow 1$} & 0.516 & $0.68 \%$ \\
\hline & \multicolumn{2}{|c|}{ Trimmed means } \\
\hline $2 \rightarrow 2$ & 1.000 & $5.50 \%$ \\
\hline $2 \rightarrow 1$ (widow) & 0.776 & $-11.74 \%$ \\
\hline \multicolumn{3}{|l|}{$2 \rightarrow 1$ (divorce) } \\
\hline \multirow[t]{2}{*}{$1 \rightarrow 1$} & 0.483 & $1.44 \%$ \\
\hline & \multicolumn{2}{|c|}{ Medians } \\
\hline $2 \rightarrow 2$ & 1.000 & $1.59 \%$ \\
\hline $2 \rightarrow 1$ (widow) & 0.747 & $-5.92 \%$ \\
\hline \multicolumn{3}{|l|}{$2 \rightarrow 1$ (divorce) } \\
\hline $1 \rightarrow 1$ & 0.424 & $-0.59 \%$ \\
\hline \multicolumn{3}{|c|}{$\begin{array}{l}\text { *Note: For the trimmed means this is the difference between } \\
\text { beginning mean and ending mean assets, as a percent of } \\
\text { beginning mean assets, averaged over the seven intervals. For } \\
\text { medians this is the median change in assets within an interval as } \\
\text { a percent of median beginning assets, averaged over the seven } \\
\text { intervals.averaged over the seven intervals. }\end{array}$} \\
\hline
\end{tabular}

Recall that households in the HRS cohort were between the ages of 51 and 61 in 1992 and between 75 and 85 in 2006. Persons in this older AHEAD cohort were 70 to 80 in 1993 and they were 83 to 93 in 2006 . Thus there is 
some age overlap between the two cohorts, for example, the original HRS cohort contains households aged 70 to 75 in 2006 and the AHEAD cohort contains households aged 70 to 75 in 1993. For ease of comparison, Figure 3-3 shows, in the same figure, the evolution of assets for HRS respondents age 56 to 61 in 1992, who were 70 to 75 in 2006, and the AHEAD respondents who were 70 to 75 in 1993, based on the trimmed mean sample. Analogous results based on medians are presented in Figure 3-4.

\section{Figure 3-3. Mean total assets for HRS persons age 56 to 61 in 1992, and AHEAD persons 70 to 75 in 1993 trimmed}

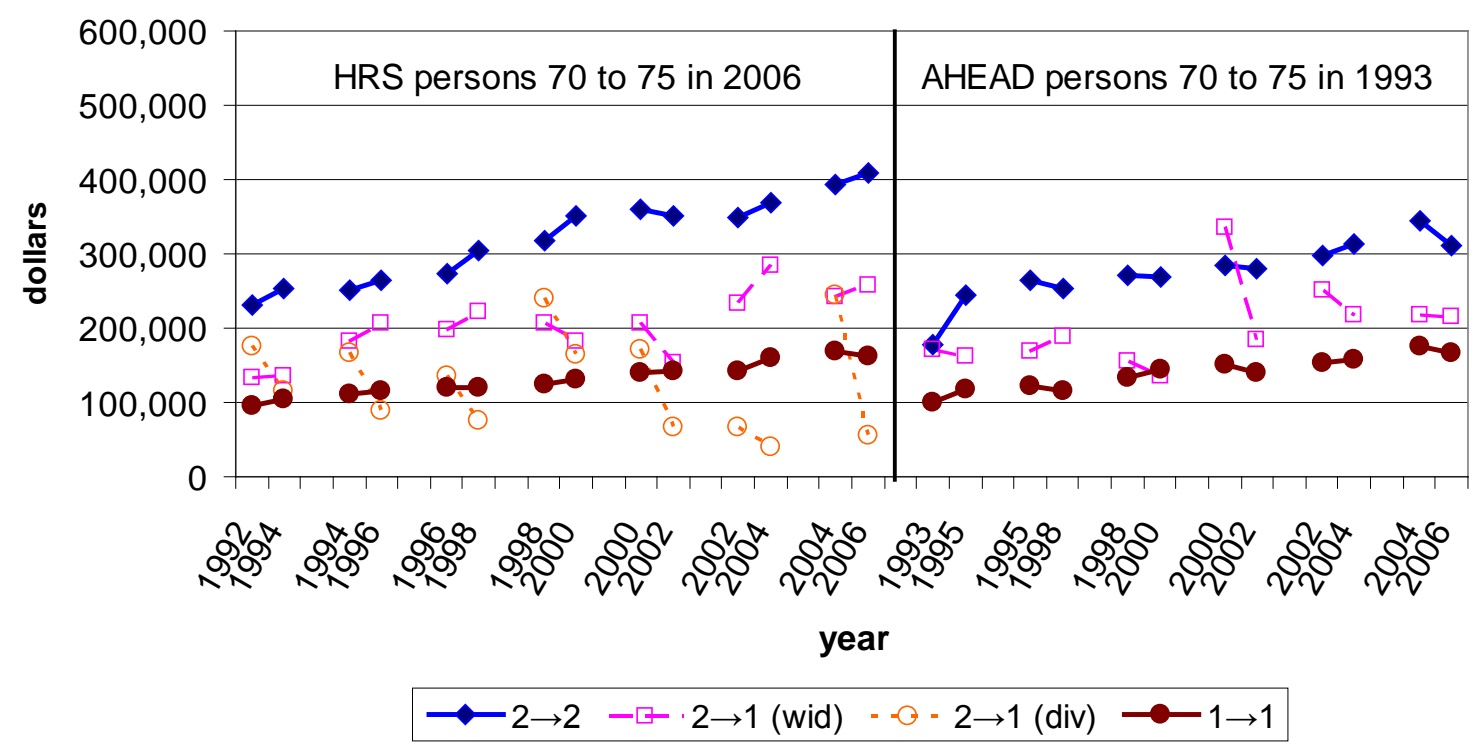




\section{Figure 3-4. Median total assets for HRS persons age 56 to 61 in 1992, and AHEAD persons 70 to 75 in 1993}

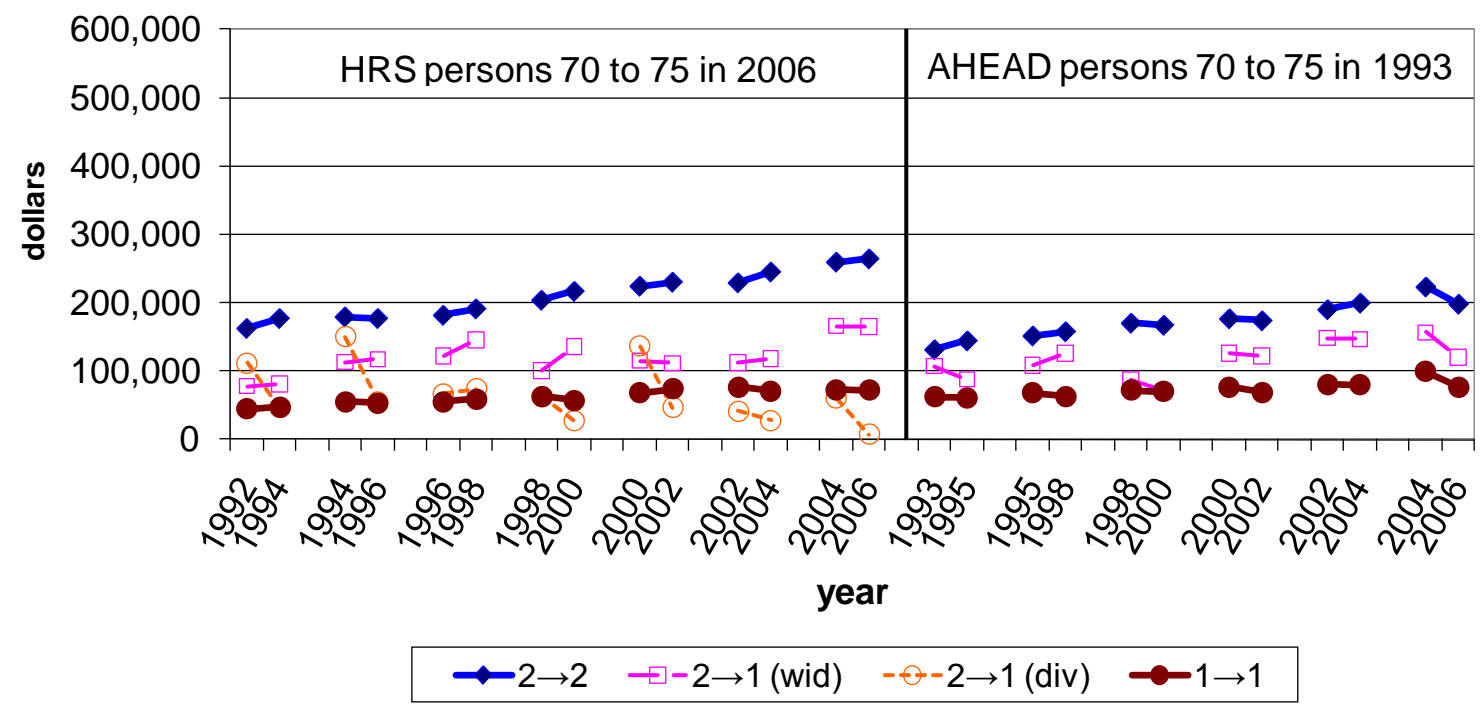

The difference between the two cohorts, the "cohort effects," are evident in the figures as the "seam" between the HRS and AHEAD cohorts. Persons who attained ages between 70 and 75 in 2006 had much greater assets (in year 2000 dollars) than persons who had attained ages between 70 to 75 thirteen years earlier in 1993. The cohort effect is particularly large for the $2 \rightarrow 2$ transition group. 


\begin{tabular}{|c|c|c|c|c|}
\hline \multirow[b]{2}{*}{$\begin{array}{l}\text { Family status } \\
\text { transition } \\
\text { group }\end{array}$} & \multicolumn{2}{|c|}{ HRS 56 to 61} & \multicolumn{2}{|c|}{ AHEAD 70 to 75} \\
\hline & $\begin{array}{l}\text { Average of } \\
\text { beginning } \\
\text { assets } \\
\text { relative to } \\
2 \rightarrow 2\end{array}$ & $\begin{array}{c}\text { Average \% } \\
\text { increase } \\
\text { over } 7 \\
\text { intervals* }\end{array}$ & $\begin{array}{l}\text { Average of } \\
\text { beginning } \\
\text { assets } \\
\text { relative to } \\
2 \rightarrow 2\end{array}$ & $\begin{array}{c}\text { Average \% } \\
\text { increase } \\
\text { over } 6 \\
\text { intervals* }\end{array}$ \\
\hline & \multicolumn{4}{|c|}{ Means } \\
\hline $2 \rightarrow 2$ & 1.000 & $8.59 \%$ & 1.000 & $4.94 \%$ \\
\hline $2 \rightarrow 1$ (widow) & 0.654 & $1.86 \%$ & 0.768 & $-6.76 \%$ \\
\hline $2 \rightarrow 1$ (divorce) & 0.656 & $-35.30 \%$ & & \\
\hline \multirow[t]{2}{*}{$1 \rightarrow 1$} & 0.413 & $4.84 \%$ & 0.520 & $2.18 \%$ \\
\hline & \multicolumn{4}{|c|}{ Trimmed means } \\
\hline $2 \rightarrow 2$ & 1.000 & $6.27 \%$ & 1.000 & $4.62 \%$ \\
\hline $2 \rightarrow 1$ (widow) & 0.648 & $2.54 \%$ & 0.701 & $-5.83 \%$ \\
\hline $2 \rightarrow 1$ (divorce) & 0.565 & $-47.58 \%$ & & \\
\hline \multirow[t]{2}{*}{$1 \rightarrow 1$} & 0.415 & $4.22 \%$ & 0.514 & $1.42 \%$ \\
\hline & \multicolumn{4}{|c|}{ Medians } \\
\hline $2 \rightarrow 2$ & 1.000 & $2.48 \%$ & 1.000 & $1.94 \%$ \\
\hline $2 \rightarrow 1$ (widow) & 0.558 & $2.57 \%$ & 0.705 & $-7.94 \%$ \\
\hline $2 \rightarrow 1$ (divorce) & 0.459 & $-22.55 \%$ & & \\
\hline $1 \rightarrow 1$ & 0.302 & $-0.02 \%$ & 0.440 & $-0.48 \%$ \\
\hline \multicolumn{5}{|c|}{$\begin{array}{l}\text { *Note: For the trimmed means this is the difference between beginning mean and } \\
\text { ending mean assets, as a percent of beginning mean assets, averaged over the } \\
\text { seven intervals. For medians this is the median change in assets within an interval } \\
\text { as a percent of median beginning assets, averaged over the intervals. }\end{array}$} \\
\hline
\end{tabular}

The evolution of assets for the two groups is summarized in Table 3-2. Several features stand out. First, for persons in both $2 \rightarrow 2$ and $1 \rightarrow 1$ groups the average percent increase in mean assets is substantially lower for the 70 to 75 age cohort than for the 56 to 61 age cohort. There is little difference in the median percent change in the assets of the younger and older $1 \rightarrow 1$ groups, however. Both are close to zero- 0.0 percent for the HRS cohort and -0.48 percent for the AHEAD cohort. Second, for both age groups and for each of the estimation procedures persons who will become widows over an interval-the $2 \rightarrow 1$ (widow) group - start the interval with lower assets than those who will continue in two-person households. Third, for both estimation procedures, assets of the older $2 \rightarrow 1$ (widow) group decline. 


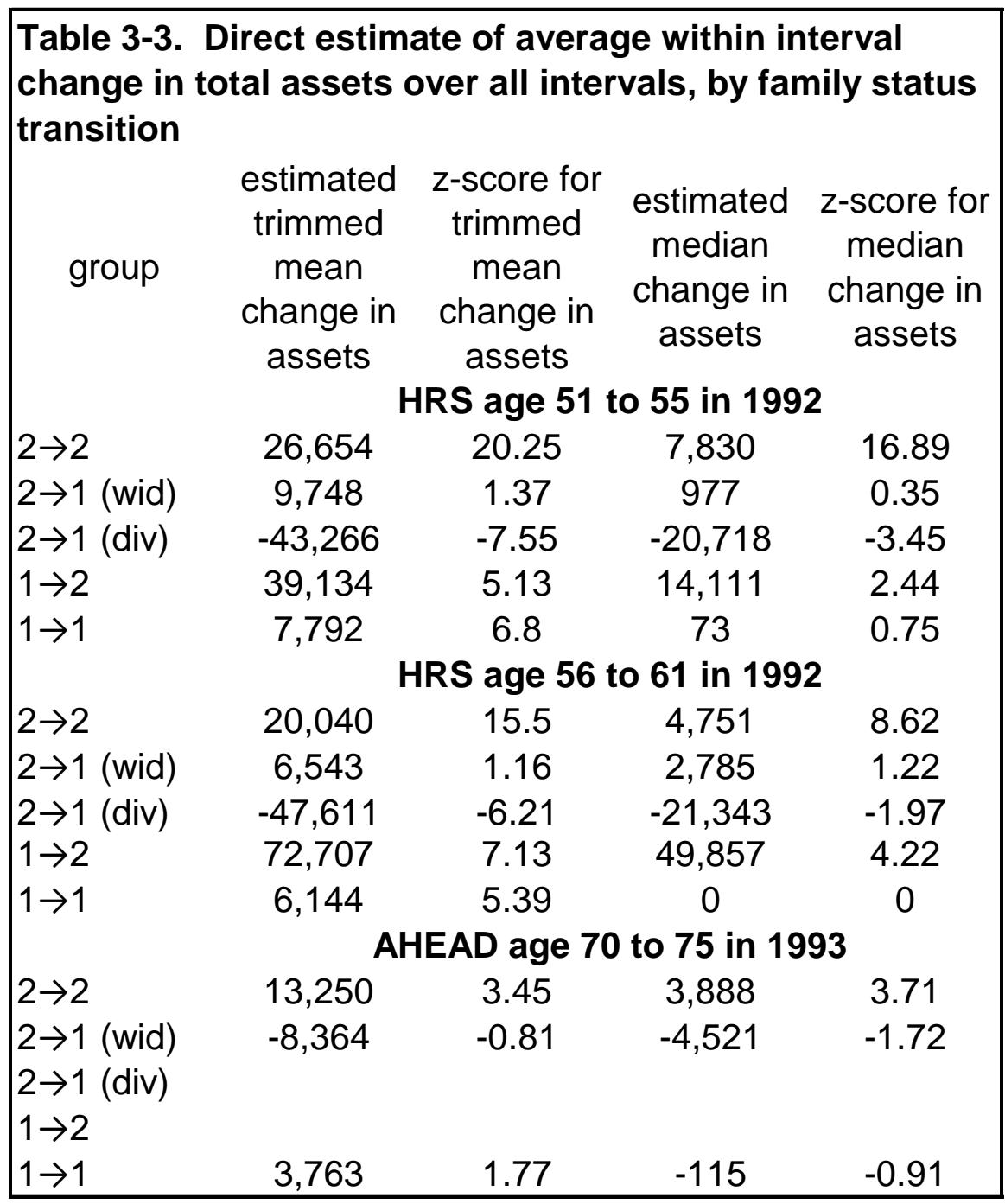

Finally, to provide a concise summary of the evolution of assets and to provide an estimate of the statistical significance of our findings for the HRS and AHEAD cohorts, we show estimates of the average within interval change in assets over all intervals. To do this we have estimated GLS regressions and median regressions of the change in assets over all intervals. That is, we combine the seven intervals to obtain a single estimate of the average change over all intervals. The estimates based on trimmed means are presented in the first column of Table 3-3. The method of trimming is the same as that described above. In this case, we estimate a GLS regression like equation (1), but the dependent variable is the change in assets for each interval. This procedure is in contrast to our earlier approach of estimating one regression for beginning assets and another second for ending assets. The median estimates are presented in the second column of Table 3-3. Both the trimmed mean and median estimates of the change in assets for $2 \rightarrow 2$ persons are positive for all age groups and all estimates are statistically significantly different from zero. The trimmed mean assets of the $1 \rightarrow 1$ group also increase for all age groups but the estimate for the AHEAD cohort is not statistically different from zero at the $5 \%$ level. All of the 
median estimates for the $1 \rightarrow 1$ group are close to, and statistically indistinguishable from, zero. The trimmed mean and median assets for the $2 \rightarrow 1$ (wid) group increase for the HRS cohorts but decline for the AHEAD cohort. We cannot reject the null hypothesis that all of these differences are equal to zero at conventional levels of statistical significance. On the other hand, the trimmed mean and median estimates of assets of the $2 \rightarrow 1$ (div) group decline substantially for the HRS cohorts. In contrast, for the $1 \rightarrow 2$ group for the HRS cohorts, the increase in the trimmed mean and median assets is large and statistically significantly different from zero.

\section{Past and Future Assets}

The results reported above show the change in total assets that is coincident with a change in family status. We considered, for example, assets at the beginning and end of a two-year interval, as well as the change in assets over the two-year interval, for persons who are in continuing two- or one-person families over the interval, or who transition from a two- to a one-person family during the interval. We now consider the assets of these same persons prior to the beginning of the interval and after the end of the interval in which the family status transition occurs. That is, we want to consider the past and future assets of persons who experience a transition within a particular interval. What were asset balances in the years preceding the transition and what were asset balances in the years subsequent to the transition?

Table 4-1 shows total asset data for HRS respondents age 56 to 61 in 1992 for all seven intervals, identified by the interval in which the family status change occurred. This transition interval is denoted the base interval. The assets of the people who experienced each type of family status transition are reported for intervals before and after the base interval. For example, the first of seven panels of the table shows beginning and ending assets in first interval and the last interval whose family status changed in the first interval, 1992 to 1994. The fourth panel shows prior and future assets of persons that changed family status in the fourth interval, 1998-2000. The seventh panel shows the prior assets of persons whose family status change is reported for the last interval, 2004 to 2006. Each panel shows asset balances for persons in each family status group in the base period. These persons may be in other family status groups in periods other than the base period. Thus, for example, the first row of Table 4-1 pertains to persons who remained in two-person households $(2 \rightarrow 2)$ for the 1992-1994 interval. Some of the persons shown in this row may have divorced or become widowed in future years. 


\begin{tabular}{|c|c|c|c|c|c|c|c|}
\hline \multirow{4}{*}{$\begin{array}{l}\text { Year of family } \\
\text { status } \\
\text { transition } \\
1992-1994\end{array}$} & \multirow{4}{*}{$\begin{array}{l}\text { Family status } \\
\text { transition }\end{array}$} & \multicolumn{6}{|c|}{ Median total assets (in 000's) } \\
\hline & & \multicolumn{2}{|c|}{ 1992-1994 } & \multicolumn{2}{|c|}{$\begin{array}{l}\text { in year of family } \\
\text { status transition }\end{array}$} & \multicolumn{2}{|c|}{ 2004-2006 } \\
\hline & & $\begin{array}{l}\text { beginnin } \\
\mathrm{g} \text { assets }\end{array}$ & $\begin{array}{l}\text { ending } \\
\text { assets }\end{array}$ & $\begin{array}{l}\text { begin- } \\
\text { ning } \\
\text { assets }\end{array}$ & $\begin{array}{l}\text { ending } \\
\text { assets }\end{array}$ & $\begin{array}{l}\text { beginnin } \\
\text { g assets }\end{array}$ & $\begin{array}{l}\text { ending } \\
\text { assets }\end{array}$ \\
\hline & & & & & & & \\
\hline & $2 \rightarrow 2$ & 163 & 177 & 163 & 177 & 238 & 241 \\
\hline & $2 \rightarrow 1$ (widowed) & 78 & 81 & 78 & 81 & 94 & 82 \\
\hline & $2 \rightarrow 1$ (divorced) & 112 & 46 & 112 & 46 & 121 & 76 \\
\hline & $1 \rightarrow 1$ & 44 & 47 & 44 & 47 & 67 & 64 \\
\hline \multicolumn{8}{|l|}{ |1996-1996 } \\
\hline & $2 \rightarrow 2$ & 164 & 181 & 180 & 177 & 244 & 244 \\
\hline & $2 \rightarrow 1$ (widowed) & 107 & 113 & 113 & 118 & 86 & 112 \\
\hline & $2 \rightarrow 1$ (divorced) & 102 & 159 & 150 & 55 & 37 & 121 \\
\hline & $1 \rightarrow 1$ & 49 & 56 & 56 & 53 & 68 & 67 \\
\hline \multicolumn{8}{|l|}{ 1996-1998 } \\
\hline & $2 \rightarrow 2$ & 171 & 186 & 182 & 191 & 247 & 249 \\
\hline & $2 \rightarrow 1$ (widowed) & 123 & 139 & 122 & 145 & 138 & 122 \\
\hline & $2 \rightarrow 1$ (divorced) & 90 & 64 & 67 & 74 & 104 & 54 \\
\hline & $1 \rightarrow 1$ & 53 & 58 & 55 & 59 & 68 & 69 \\
\hline \multicolumn{8}{|l|}{$1998-2000$} \\
\hline & $2 \rightarrow 2$ & 177 & 191 & 204 & 217 & 254 & 254 \\
\hline & $2 \rightarrow 1$ (widowed) & 121 & 110 & 100 & 136 & 144 & 161 \\
\hline & $2 \rightarrow 1$ (divorced) & 215 & 210 & 63 & 27 & 21 & 10 \\
\hline & $1 \rightarrow 1$ & 61 & 65 & 63 & 57 & 71 & 71 \\
\hline \multicolumn{8}{|l|}{$2000-2002$} \\
\hline & $2 \rightarrow 2$ & 180 & 195 & 225 & 230 & 257 & 259 \\
\hline & $2 \rightarrow 1$ (widowed) & 130 & 152 & 115 & 111 & 98 & 110 \\
\hline & $2 \rightarrow 1$ (divorced) & 93 & 138 & 136 & 46 & 85 & 26 \\
\hline & $1 \rightarrow 1$ & 65 & 71 & 68 & 74 & 72 & 73 \\
\hline \multicolumn{8}{|l|}{ 2002-2004 } \\
\hline & $2 \rightarrow 2$ & 182 & 195 & 230 & 245 & 257 & 259 \\
\hline & $2 \rightarrow 1$ (widowed) & 131 & 124 & 112 & 119 & 159 & 175 \\
\hline & $2 \rightarrow 1$ (divorced) & 26 & 55 & 41 & 28 & 32 & 189 \\
\hline & $1 \rightarrow 1$ & 70 & 76 & 77 & 71 & 72 & 71 \\
\hline \multicolumn{8}{|l|}{$2004-2006$} \\
\hline & $2 \rightarrow 2$ & 189 & 203 & 260 & 264 & 260 & 264 \\
\hline & $2 \rightarrow 1$ (widowed) & 182 & 165 & 166 & 165 & 166 & 165 \\
\hline & $2 \rightarrow 1$ (divorced) & 114 & 57 & 60 & 7 & 60 & 7 \\
\hline & $1 \rightarrow 1$ & 75 & 78 & 73 & 72 & 73 & 72 \\
\hline
\end{tabular}

The asset patterns are difficult to distinguish in the table, but are more easily seen in figures. Figures 4-1, 4-2, and 4-3 show assets pertaining to the first, fourth, and seventh panels of the table. In each figure, the year in which the asset change occurred, the base interval, is highlighted in a box. For ease of exposition we show only the assets for three groups, $2 \rightarrow 2,2 \rightarrow 1$ (wid), and $1 \rightarrow 1$, and emphasize the assets of the $2 \rightarrow 1$ (wid) group compared to the $2 \rightarrow 2$ group. The key finding is that two-person household that will experience a $2 \rightarrow 1$ (wid) transition during the 1992 to 2006 period had lower assets than continuing $2 \rightarrow 2$ households long before the transition occurred. Thus for the $2 \rightarrow 1$ (wid) group the 
finding that pre- and post-transition asset levels are low is an important message that complements that finding of the drop in assets at the time of the transition.

Consider first Figure 4-3, which shows the assets in each interval of persons by family status transition group in the last (2004-2006) interval. First compare the assets of persons in the $2 \rightarrow 2$ group to the assets of persons in the $2 \rightarrow 1$ (wid) group. In the last interval, in which the change in family status occurred, the assets of persons in the $2 \rightarrow 1$ (wid) group were much lower than the assets of persons in the $2 \rightarrow 2$ group. But the assets of the $2 \rightarrow 1$ (wid) group had been lower for most of the 14 prior years. In 1992 the assets of these two groups were similar, but over the next 14 years the assets of the $2 \rightarrow 2$ group increased substantially, while the assets of the $2 \rightarrow 1$ (wid) group changed little, on balance. That is, the assets of persons who would experience a $2 \rightarrow 1$ (wid) transition many years in the future did not change much in the years prior to the transition, while the assets of the persons who were to experience a $2 \rightarrow 2$ transition in the future increased substantially in prior years. (The relationships for the other base intervals are similar in this respect, but for the other intervals, the assets of the $2 \rightarrow 1$ (wid) group were much lower than the assets for the $2 \rightarrow 2$ group.)

Moving to the Figure 4-1, we can follow the future assets of persons who changed family status in the first interval (1992-1994). We see that the assets of the $2 \rightarrow 2$ group in the first interval continued to increase in all of the later periods. The initial wealth of this group was $\$ 177,439$ at the end of the first interval in 1994 and $\$ 241,431$ at the end of 2006 (in year 2000 dollars), an increase of 36.1 percent over the next 12 years. Persons whose spouse died between 1992 and 1994 , the $2 \rightarrow 1$ (wid) group, had assets about half the level of the $2 \rightarrow 2$ group in the first interval and the surviving persons in this group had only a small increase in assets over the next 14 years, about 2.0 percent. The $1 \rightarrow 1$ group in the first interval experienced a 34.0 percent increase in assets over the next 12 years.

Figure 4-2 shows the prior and subsequent assets of persons who changed family status in 1998-2000. The assets of the $2 \rightarrow 2$ group were increasing in each of the prior three intervals and continued to increase in each of the three subsequent intervals. The $2 \rightarrow 1$ (widowed) group had much lower assets than the $2 \rightarrow 2$ group in the prior three intervals and continued to have much lower assets in the future three intervals. The patterns for the other intervals are much like the patterns revealed in three intervals discussed.

Finally, we want to emphasize that the sequence of family status transitions can be quite complicated. To demonstrate this feature of the data, we use the prior and future family status transition of persons with base transitions in 1998-2000, those represented in Figure 4-2. For example, the first panel of Table 4-2 shows the percent distribution of the family status transition groups of persons who were in the $2 \rightarrow 2$ group in 1998-2000. The entries in bold in the first 
row show that most of those in the $2 \rightarrow 2$ group in the base year were also in the $2 \rightarrow 2$ group in the prior three intervals and in the subsequent three intervals.

Figure 4-1. Median total assets by household status change in 1992-1994, persons age 56-61 in 1992

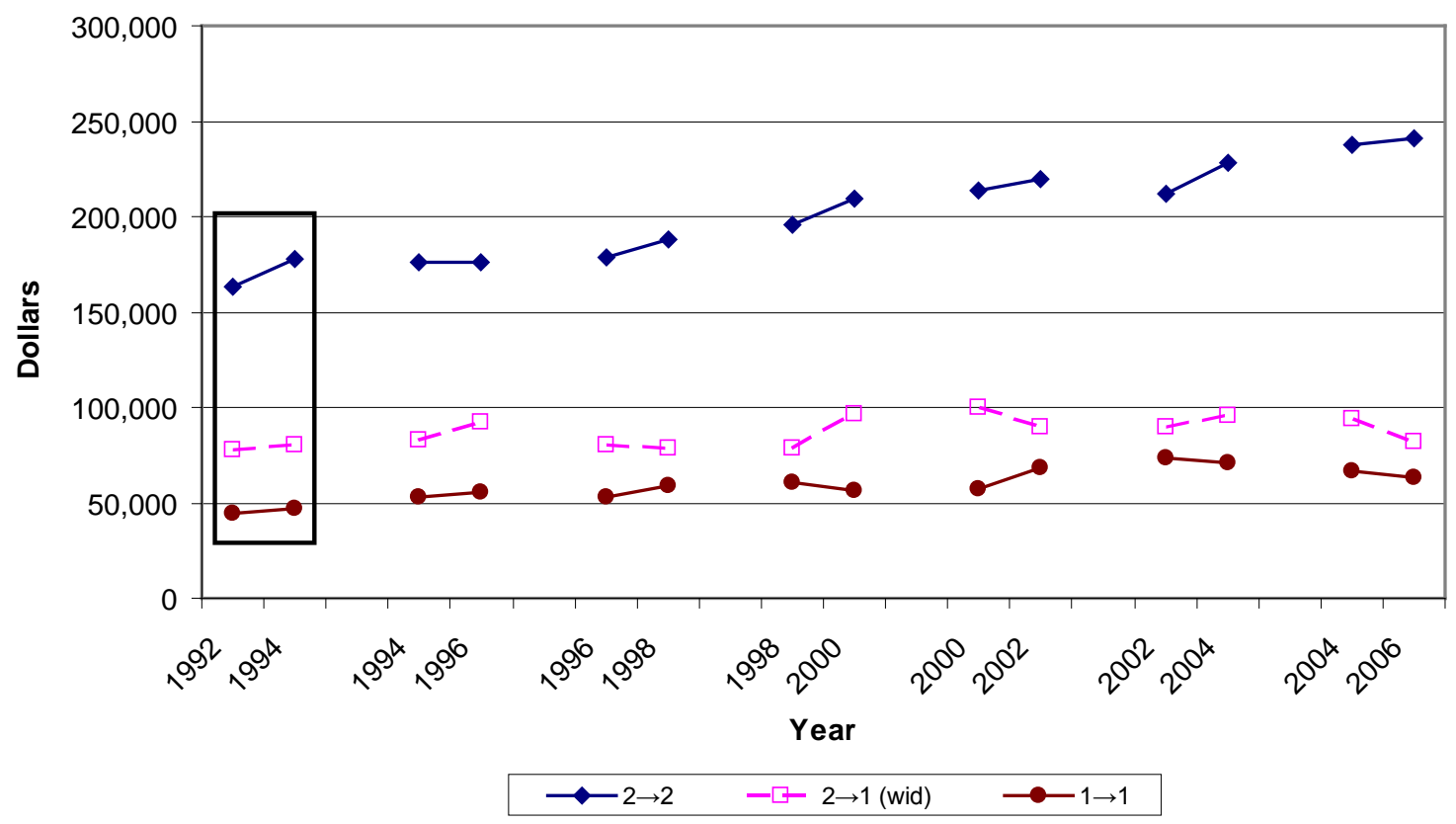

Figure 4-2. Median total assets by household status change in 1998-2000, persons age 56-61 in 1992

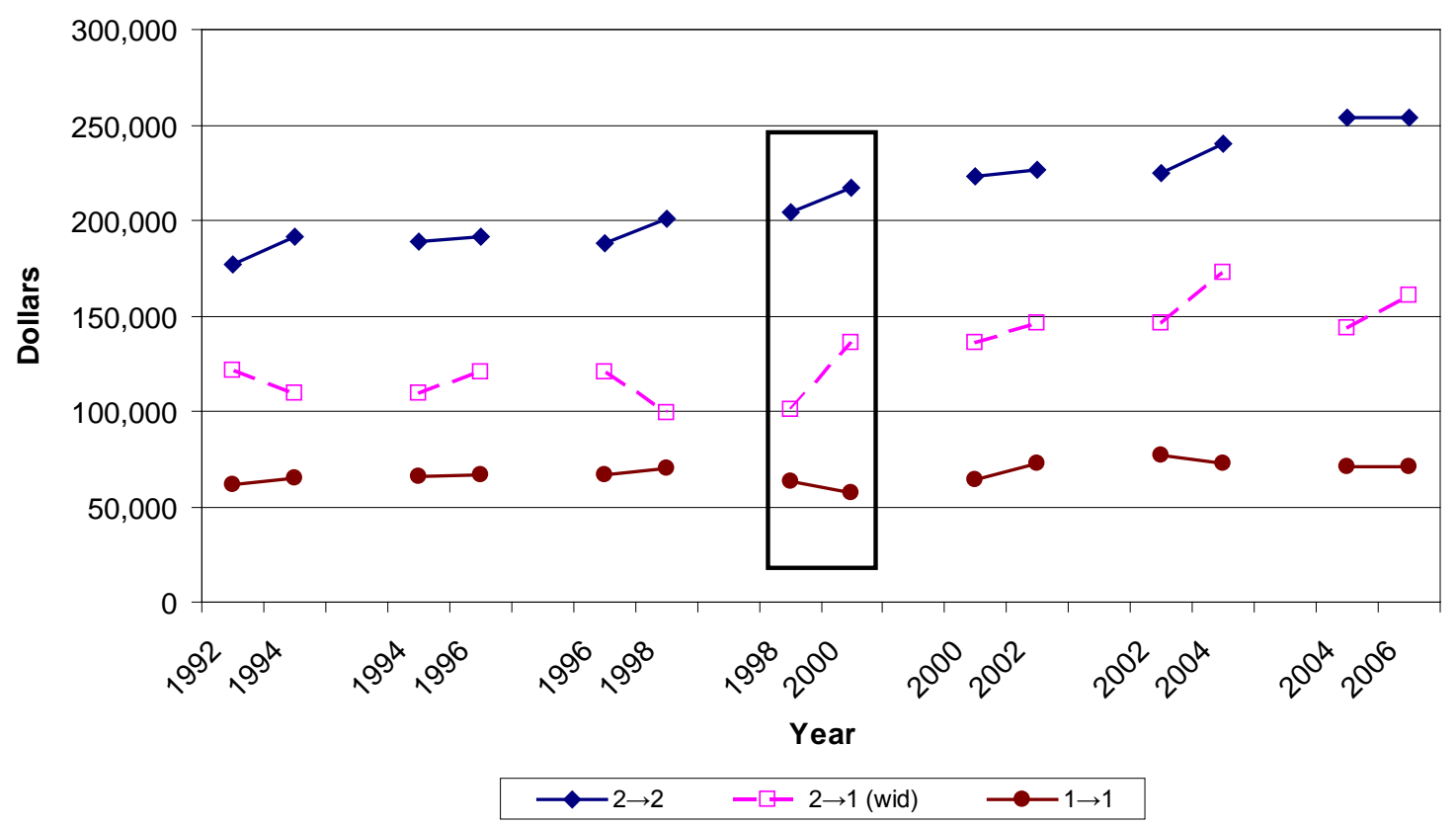


Figure 4-3. Median total assets by household status change in 2004-2006, persons age 56-61 in 1992

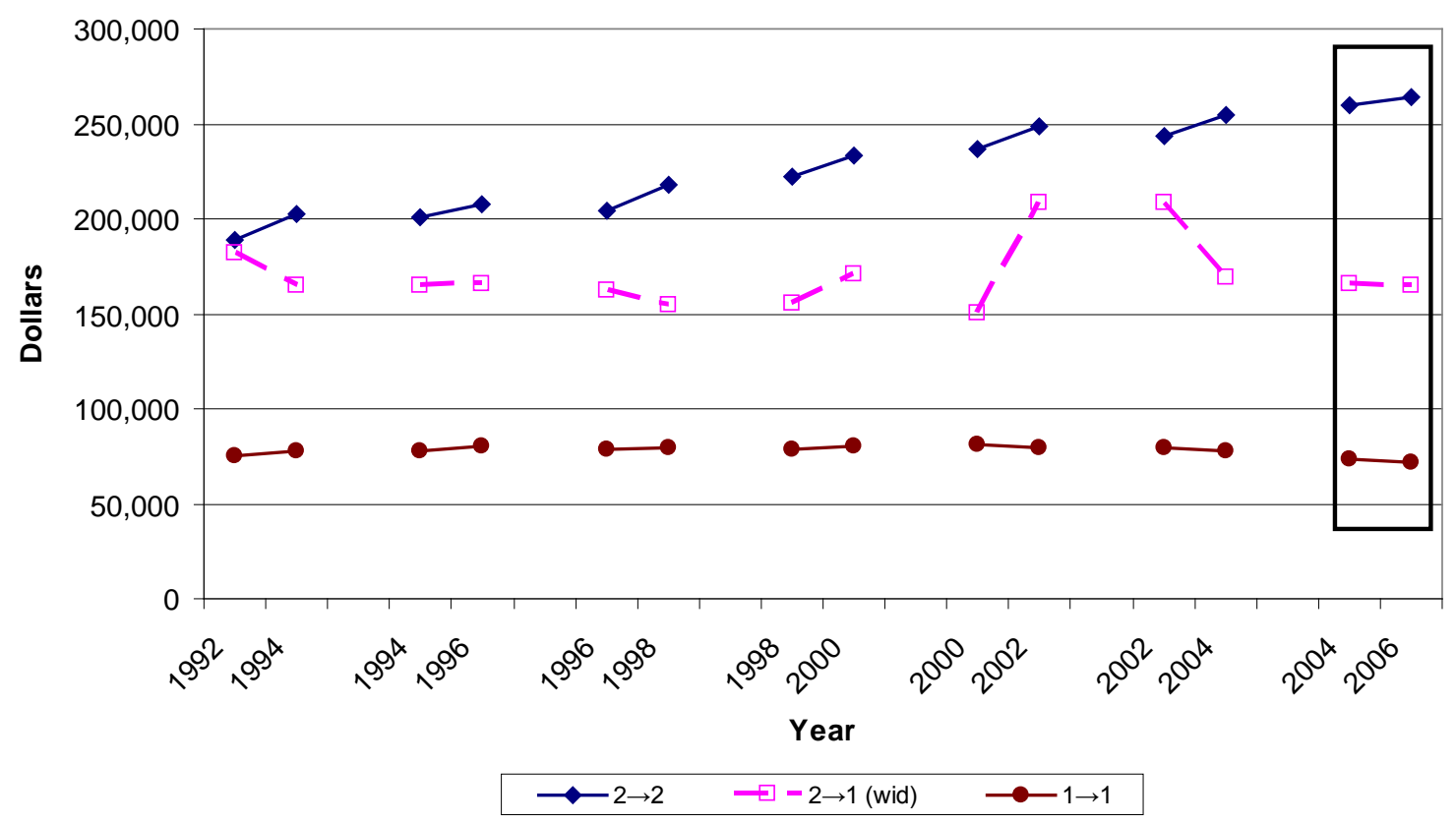

One might suppose that that those in the $2 \rightarrow 1$ (wid) group in the base year (in the second panel of the table) would typically be in the $2 \rightarrow 2$ group in prior intervals, as they are. One might also expect that they would be in the $1 \rightarrow 1$ group in subsequent years. But this is not so certain. We see that 10.3 percent are in the $1 \rightarrow 2$ group in the next interval, suggesting that they remarried during the next interval. And by the following interval, 13.7 percent were once again in the $2 \rightarrow 2$ group.

The $2 \rightarrow 1$ (div) group (in the third panel) also follow disparate transitions before and after the base transition. For example, 21.4 percent were in the $1 \rightarrow 2$ group in the prior interval, suggesting that they were married in the prior interval. Another 25 percent were in the $1 \rightarrow 2$ group in the following interval, suggesting that they remarried in the interval just after the base interval.

We have emphasized the errors in asset reporting. It may also be that there are errors in reports of family status as well, and we will need to pursue this issue further in future work 


\begin{tabular}{|c|c|c|c|c|c|c|c|}
\hline \multirow[t]{2}{*}{ group } & $\begin{array}{c}1992- \\
1994\end{array}$ & $\begin{array}{c}1994- \\
1996\end{array}$ & $\begin{array}{c}1996- \\
1998\end{array}$ & $\begin{array}{c}1998- \\
2000\end{array}$ & $\begin{array}{l}2000- \\
2002\end{array}$ & $\begin{array}{c}2002- \\
2004\end{array}$ & $\begin{array}{c}2004- \\
2006\end{array}$ \\
\hline & \multicolumn{7}{|c|}{ group $2 \rightarrow 2$ in $1998-2000$} \\
\hline $2 \rightarrow 2$ & 97.1 & 97.4 & 98.9 & 100.0 & 96.8 & 93.8 & 89.5 \\
\hline $2 \rightarrow 1$ (wid) & 0.3 & 0.2 & 0.0 & 0.0 & 2.7 & 2.7 & 4.0 \\
\hline $2 \rightarrow 1$ (div) & 0.7 & 0.2 & 0.0 & 0.0 & 0.5 & 0.3 & 0.7 \\
\hline $2 \rightarrow 1$ & 0.7 & 1.5 & 1.1 & 0.0 & 0.0 & 0.4 & 0.5 \\
\hline \multirow[t]{2}{*}{$1 \rightarrow 1$} & 1.2 & 0.8 & 0.0 & 0.0 & 0.0 & 2.8 & 5.5 \\
\hline & \multicolumn{7}{|c|}{ group $2 \rightarrow 1$ (wid) in $1998-2000$} \\
\hline $2 \rightarrow 2$ & 96.7 & 97.5 & 100.0 & 0.0 & 0.0 & 13.7 & 9.4 \\
\hline $2 \rightarrow 1$ (wid) & 0.0 & 0.0 & 0.0 & 100.0 & 0.0 & 0.0 & 0.0 \\
\hline $2 \rightarrow 1$ (div) & 0.0 & 0.0 & 0.0 & 0.0 & 0.0 & 0.0 & 0.0 \\
\hline $2 \rightarrow 1$ & 0.9 & 2.5 & 0.0 & 0.0 & 10.3 & 2.3 & 0.0 \\
\hline \multirow[t]{2}{*}{$1 \rightarrow 1$} & 2.4 & 0.0 & 0.0 & 0.0 & 89.7 & 84.0 & 90.6 \\
\hline & \multicolumn{7}{|c|}{ group $2 \rightarrow 1$ (div) in $1998-2000$} \\
\hline $2 \rightarrow 2$ & 72.8 & 65.7 & 78.6 & 0.0 & 0.0 & 11.6 & 15.0 \\
\hline $2 \rightarrow 1$ (wid) & 0.0 & 0.0 & 0.0 & 0.0 & 0.0 & 0.0 & 0.0 \\
\hline $2 \rightarrow 1$ (div) & 0.0 & 5.8 & 0.0 & 100.0 & 0.0 & 0.0 & 3.6 \\
\hline $2 \rightarrow 1$ & 0.0 & 13.7 & 21.4 & 0.0 & 25.0 & 6.9 & 0.0 \\
\hline \multirow[t]{2}{*}{$1 \rightarrow 1$} & 27.2 & 14.8 & 0.0 & 0.0 & 75.0 & 81.5 & 81.5 \\
\hline & \multicolumn{7}{|c|}{ group $1 \rightarrow 2$ in $1998-2000$} \\
\hline $2 \rightarrow 2$ & 33.0 & 25.6 & 0.0 & 0.0 & 91.3 & 83.7 & 75.9 \\
\hline $2 \rightarrow 1$ (wid) & 1.2 & 5.6 & 15.1 & 0.0 & 4.0 & 7.4 & 0.0 \\
\hline $2 \rightarrow 1$ (div) & 7.8 & 4.7 & 13.1 & 0.0 & 4.6 & 6.6 & 1.9 \\
\hline $2 \rightarrow 1$ & 0.0 & 0.0 & 0.0 & 100.0 & 0.0 & 0.0 & 0.0 \\
\hline \multirow[t]{2}{*}{$1 \rightarrow 1$} & 58.0 & 64.1 & 71.7 & 0.0 & 0.0 & 2.3 & 22.2 \\
\hline & \multicolumn{7}{|c|}{ group $1 \rightarrow 1$ in $1998-2000$} \\
\hline $2 \rightarrow 2$ & 18.0 & 10.0 & 0.0 & 0.0 & 0.0 & 1.1 & 1.4 \\
\hline $2 \rightarrow 1$ (wid) & 4.6 & 5.7 & 9.2 & 0.0 & 0.0 & 0.2 & 0.3 \\
\hline $2 \rightarrow 1$ (div) & 2.3 & 1.6 & 1.4 & 0.0 & 0.0 & 0.2 & 0.0 \\
\hline $2 \rightarrow 1$ & 0.7 & 0.2 & 0.0 & 0.0 & 1.5 & 2.1 & 1.4 \\
\hline $1 \rightarrow 1$ & 74.4 & 82.4 & 89.4 & 100.0 & 98.5 & 96.5 & 96.9 \\
\hline
\end{tabular}

In summary, we conclude that households that continue as two-person households $(2 \rightarrow 2)$ in any of the seven two-year intervals not only increase total assets in that interval and also typically experience an increase in assets in all prior and subsequent intervals. The same pattern typically holds for continuing one-person $(1 \rightarrow 1)$ households as well. We also find that the asset history of twoperson households that experience a change in family status -- $2 \rightarrow 1$ (wid) -- is very different from the history of continuing two-person families. The $2 \rightarrow 1$ (wid) 
group have much lower assets than persons in $2 \rightarrow 2$ households in the interval during witch they experienced the transition, but this group also had much lower assets than persons in continuing two-person households long before they experienced the change in family status.

\section{The SIPP Cohort Estimates}

Recall that the total assets based on HRS and AHEAD data exclude 401(k) assets that have not been rolled over into an IRA. To determine whether the general trends seem to be the same when $401(\mathrm{k})$ assets are included, we now show assets based on SIPP data. For ease of comparison we show figures analogous to Figures 3-3 and 3-4 above that show trimmed means and medians for persons age 56 to 61 in 1992 (the HRS cohort) and for persons age 70 to 75 in 1993 (the AHEAD cohort). Because the SIPP surveys persons at all ages in each wave, these data can be "matched' to the age groups surveyed in the HRS and AHEAD cohorts. However, the years sampled in SIPP are different from the years sampled in the HRS and AHEAD. Thus, the intervals we show based on the SIPP do not exactly match the HRS and AHEAD intervals. In addition, the SIPP figures are based on one-year intervals in contrast to the two-year intervals for the HRS and AHEAD. Figure 5-1 shows the SIPP data for trimmed means and Figure 5-2 shows the SIPP data for medians. Each of the figures shows data for the same two cohorts graphed in Figures 3-3 and 3-4 above, although not for the entire time period shown for the HRS and AHEAD cohorts. Persons who were 56 to 61 in 1992 are observed six times in the SIPP, first at ages 61 to 66 in 1997 and last at ages 68 to 73 in 2004. Persons who were age 70 to 75 in 1993 are first observed in the SIPP at ages 74 to 79 in 1997 and last at ages 79 to 84 in 2002. Data for 2004 cannot be used for the older cohort because the SIPP top-codes age at 85 .

Because we observe households over a one-year interval in the SIPP, the sample size is not large enough to distinguish between $2 \rightarrow 1$ (wid) and $2 \rightarrow 1$ (div). We have combined these two transition groups into a single $2 \rightarrow 1$ group, primarily widows for the older group. The trimmed mean estimates for this group are erratic, although the medians are smoother.

The SIPP data for persons in the $1 \rightarrow 1$ and $2 \rightarrow 2$ groups show a pattern of asset change that is similar to the pattern based on the HRS and AHEAD cohorts. For persons age 56 to 61 in 1992 the asset levels for persons in the $1 \rightarrow 1$ and $2 \rightarrow 2$ groups are lower in the SIPP survey and the upward trend over time is more prominent in the HRS data. This is true for both median and trimmed mean estimates. A similar relationship between the SIPP and AHEAD data is observed for persons aged 70 to 75 in 1993. 
Figure 5-1. Mean total assets for persons age 56 to 61 in 1992, and persons 70 to 75 in 1993, trimmed SIPP data

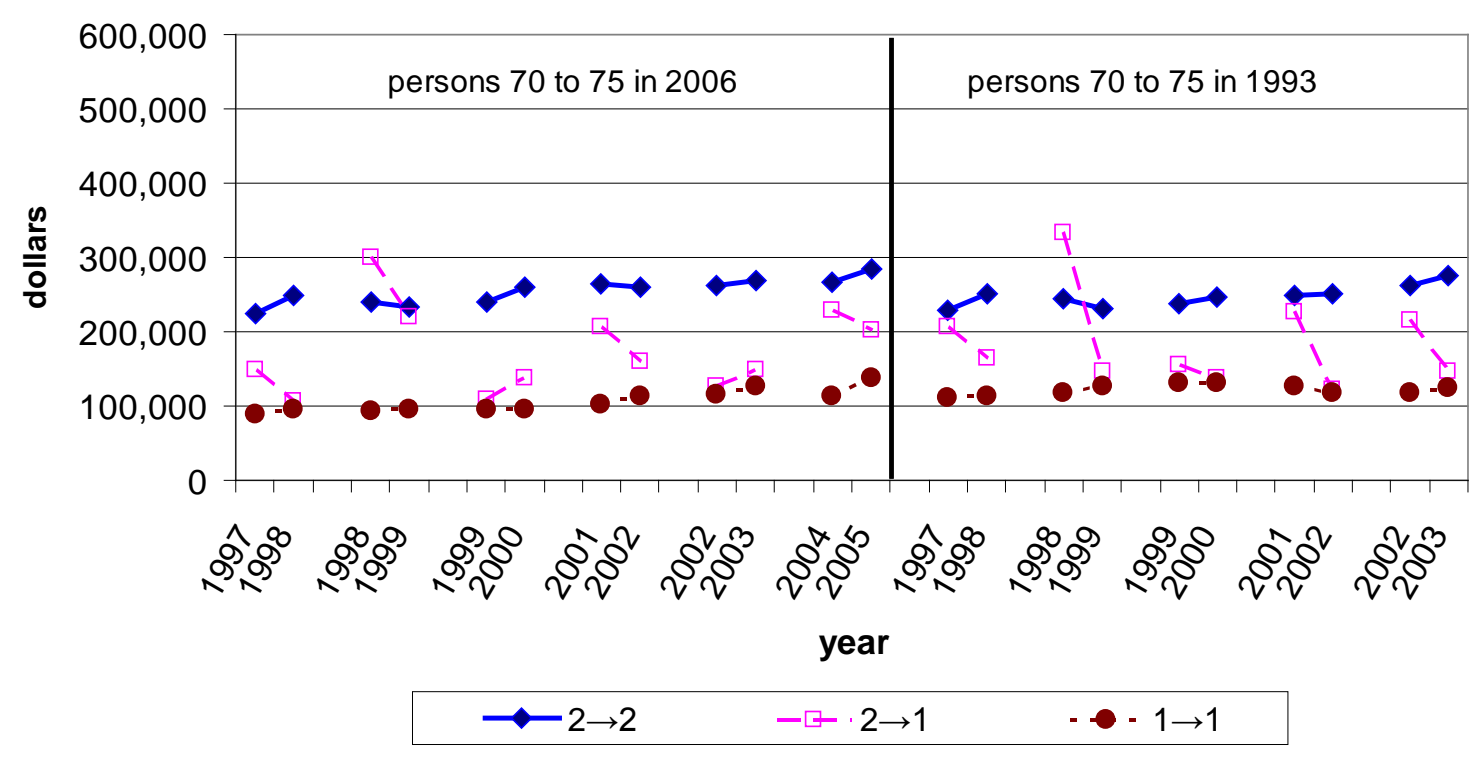

Figure 5-2. Median total assets for persons age 56 to 61 in 1992, and persons 70 to 75 in 1993, SIPP data

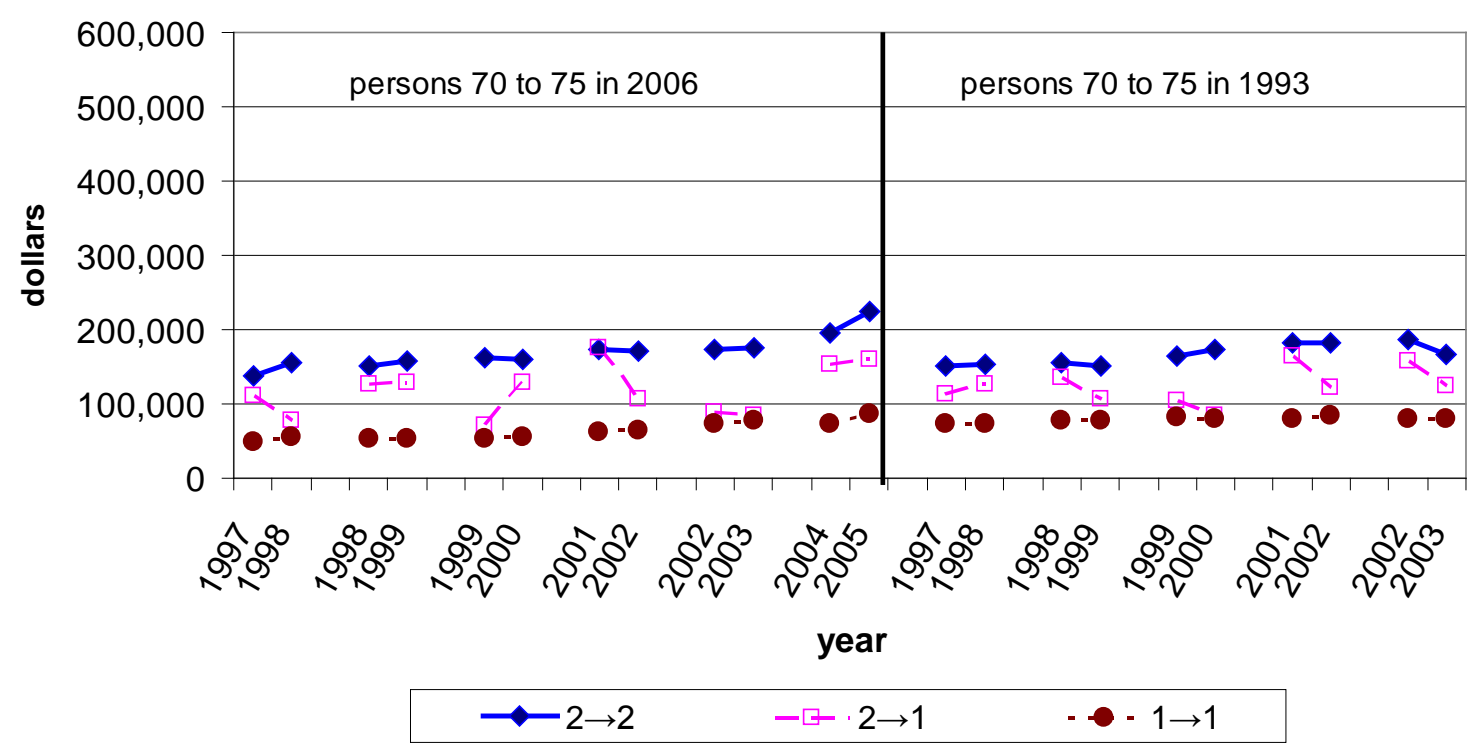

The differences between estimates based on the SIPP and the HRSAHEAD data are summarized more clearly in Tables 5-1 and 5-2. Table 5-1 
pertains to the younger cohort, age 56 to 61 in 1992. Recall that the HRS intervals are two years in length while the SIPP intervals are one year. The HRS and SIPP estimates are quite different for the $2 \rightarrow 1$ transition groups, although these comparisons are confounded because the SIPP does not distinguish widowhood from divorce. Perhaps the most notable difference between the HRS and the SIPP results is the substantially larger within-interval increase based on the SIPP data, for both the $2 \rightarrow 2$ and the $1 \rightarrow 1$ groups and for both the trimmed mean and the median estimates. It is possible that this result is due to the inclusion of 401(k) assets in the SIPP but not the HRS data. Households are likely contributing to their $401(\mathrm{k})$ plans during their working years and thereby increasing their account balances through both account inflows and potential appreciation. Recall that the SIPP increases are over one year and the HRS increases over two year. 
Table 5-1. Summary of asset changes by family status transition ( group, persons 56 to 61 in 1992 in the HRS and SIPP, in year 2000 dollars.

\begin{tabular}{|c|c|c|c|c|}
\hline \multirow[b]{2}{*}{$\begin{array}{l}\text { Family status } \\
\text { transition } \\
\text { group }\end{array}$} & \multicolumn{2}{|c|}{ HRS } & \multicolumn{2}{|c|}{ SIPP } \\
\hline & $\begin{array}{l}\text { Average of } \\
\text { beginning } \\
\text { assets } \\
\text { relative to } \\
2 \rightarrow 2\end{array}$ & $\begin{array}{l}\text { Average \% } \\
\text { increase } \\
\text { over } 5 \text { two- } \\
\text { year } \\
\text { intervals* }\end{array}$ & $\begin{array}{l}\text { Average of } \\
\text { beginning } \\
\text { assets } \\
\text { relative to } \\
2 \rightarrow 2\end{array}$ & $\begin{array}{c}\text { Average \% } \\
\text { increase } \\
\text { over } 6 \text { one- } \\
\text { year } \\
\text { intervals* }\end{array}$ \\
\hline & \multicolumn{4}{|c|}{ Trimmed means } \\
\hline $2 \rightarrow 2$ & 1.000 & $5.8 \%$ & 1.000 & $4.12 \%$ \\
\hline $2 \rightarrow 1$ (widow) & 0.645 & $0.8 \%$ & & \\
\hline $2 \rightarrow 1$ (divorce) & 0.506 & $-50.6 \%$ & & \\
\hline $2 \rightarrow 1$ (combined) & & & 0.749 & $-7.19 \%$ \\
\hline \multirow[t]{2}{*}{$1 \rightarrow 1$} & 0.411 & $3.2 \%$ & 0.407 & $7.84 \%$ \\
\hline & \multicolumn{4}{|c|}{ Medians } \\
\hline $2 \rightarrow 2$ & 1.000 & $2.0 \%$ & 1.000 & $5.52 \%$ \\
\hline $2 \rightarrow 1$ (widow) & 0.560 & $3.6 \%$ & & \\
\hline $2 \rightarrow 1$ (divorce) & 0.339 & $-18.6 \%$ & & \\
\hline $2 \rightarrow 1$ (combined) & & & 0.736 & $1.97 \%$ \\
\hline $1 \rightarrow 1$ & 0.306 & $0.0 \%$ & 0.365 & $7.85 \%$ \\
\hline \multicolumn{5}{|c|}{$\begin{array}{l}\text { Note: The HRS estimates are based on data for the } 1996-1998,1998-2000,2000 \\
2002,2002-2004 \text {, and 2004-2006 intervals. The SIPP estimates are based on } \\
\text { data for the 1997-1998, 1998-1999, 1999-2000, 2001-2002, 2002-2003, and } \\
2004-2005 \text { intervals. Note that the HRS estimates are for two year intervals and } \\
\text { the SIPP estimates are for one year intervals. }\end{array}$} \\
\hline
\end{tabular}


Table 5-2. Summary of asset changes by family status transition ( group, persons 70 to 75 in 1993 in the AHEAD and SIPP, in year 2000 dollars.

\begin{tabular}{|c|c|c|c|c|}
\hline \multirow[b]{2}{*}{$\begin{array}{l}\text { Family status } \\
\text { transition group }\end{array}$} & \multicolumn{2}{|c|}{ AHEAD } & \multicolumn{2}{|c|}{ SIPP } \\
\hline & $\begin{array}{c}\text { Average of } \\
\text { beginning } \\
\text { assets } \\
\text { relative to } \\
2 \rightarrow 2\end{array}$ & $\begin{array}{l}\text { Average \% } \\
\text { increase } \\
\text { over } 4 \text { two- } \\
\text { year } \\
\text { intervals* }\end{array}$ & $\begin{array}{l}\text { Average of } \\
\text { beginning } \\
\text { assets } \\
\text { relative to } \\
2 \rightarrow 2\end{array}$ & $\begin{array}{c}\text { Average \% } \\
\text { increase } \\
\text { over } 6 \text { one- } \\
\text { year } \\
\text { intervals* }\end{array}$ \\
\hline & \multicolumn{4}{|c|}{ Trimmed means } \\
\hline $2 \rightarrow 2$ & 1.000 & $-0.05 \%$ & 1.000 & $3.09 \%$ \\
\hline $2 \rightarrow 1$ (widow) & 0.678 & $-6.99 \%$ & & \\
\hline \multicolumn{5}{|l|}{$2 \rightarrow 1$ (divorce) } \\
\hline $2 \rightarrow 1$ (combined) & & & 0.931 & $-33.12 \%$ \\
\hline \multirow{2}{*}{$1 \rightarrow 1$} & 0.503 & $-0.61 \%$ & 0.497 & $1.46 \%$ \\
\hline & \multicolumn{4}{|c|}{ Medians } \\
\hline $2 \rightarrow 2$ & 1.000 & $1.15 \%$ & 1.000 & $-1.17 \%$ \\
\hline $2 \rightarrow 1$ (widow) & 0.679 & $-6.97 \%$ & & \\
\hline \multicolumn{5}{|l|}{$2 \rightarrow 1$ (divorce) } \\
\hline $2 \rightarrow 1$ (combined) & & & 0.801 & $-15.03 \%$ \\
\hline $1 \rightarrow 1$ & 0.431 & $-0.26 \%$ & 0.470 & $0.65 \%$ \\
\hline \multicolumn{5}{|c|}{$\begin{array}{l}\text { The AHEAD estimates are based on data for the } 1995-1998,1998-2000,2000- \\
2002, \text { and the 2002-2004 intervals. The SIPP estimates are based on data for } \\
\text { the 1997-1998, 1998-1999, 1999-2000, 2001-2002, 2002-2003 and 2004-2005, } \\
\text { intervals. Note that the AHEAD estimates are for two year intervals (except for } \\
\text { the three-year interval for 1995-1998 and the SIPP estimates are for one year } \\
\text { intervals. } \\
\text { *For the trimmed means this is the difference between beginning mean and } \\
\text { ending mean assets, as a percent of beginning mean assets, averaged over the } \\
\text { seven intervals. For medians this is the median change in assets within an } \\
\text { interval as a percent of median beginning assets, averaged over the intervals. }\end{array}$} \\
\hline
\end{tabular}

Table 5-2 pertains to the cohort aged 70 to 75 in 1993. None of the estimates for the $2 \rightarrow 2$ or the $1 \rightarrow 1$ groups differ greatly. Based on trimmed means, however, the SIPP estimates show somewhat larger percent increases than the HRS estimates for the $2 \rightarrow 2$ and the $1 \rightarrow 1$ cohorts; both estimates are slightly negative based on the HRS data.

\section{Health and Asset Accumulation: Latent Health Index}

In addition to understanding the relationship between asset evolution and family status transitions, we want to explore the relationships between health and asset evolution. Because family status transitions are likely to be correlated with the health status of the family members, it is possible that our classification of 
households by transition groups may proxy in part for underlying differences in health status. In this section and the next, we take some preliminary steps to develop an explicit measure of health status, and to investigate its relationship to the asset evolution we have described above. We begin in this section by explaining the "latent" health measure that we use. Then, in the next section, we show how differences in latent health are associated with differences in the levels and rates of change in total assets. Within family status transition groups we find very large relationships between our latent health measure and the evolution of assets.

The HRS collects substantial information on health status and changes in health status. We use this information to calculate a "latent" health index. We assume that latent health is revealed by information about health contained in responses to the health questions over the course of the survey waves. We suppose that persons with poorer "latent" health will report more poor health indicators than persons in better health. The index is used to group persons by latent health status at the beginning of each of the two-year intervals (seven intervals in the HRS and six intervals in the AHEAD) for which we observe a change in assets.

We construct a latent health index as an "evolving" index that uses information up to the beginning of each interval. For example, suppose we are considering the change in assets between the third and fourth waves of the HRS survey (between 1996 and 1998). We group persons by a health index based on health indicators available in the 1992, 1994, and 1996 waves of the HRS. If we consider the change in assets between 1992 and 1994 we construct the index from the 1992 responses. An index for the asset change between 2004 and 2006 can be constructed from the seven survey waves between 1992 and 2004. This is the procedure we follow.

The HRS contains a large number of detailed questions that can be used to construct an index of latent health. The results reported here use a latent health index based on responses to the following questions:

1. BMI at beginning of period

2. Sum of real out-of-pocket (OOP) medical costs

3. Number of periods: selfreported health fair or poor

4. Number of periods: health worse in previous period

5. Number hospital stays

6. Number of nursing home stays

7. Number of doctor visits

8. Number of periods: home care
9. Number of periods: health problems limit work

10. Number of periods with back problems

11. Number of periods with some difficulty with an ADL

12. Number of periods with difficulty walking several blocks

13. Number of periods with difficulty sitting two hours

14. Number of periods with difficulty getting up from chair 
15. Number of periods with difficulty climbing stairs

16. Number of periods with difficulty stoop/kneel/crouch

17. Number of periods with difficulty lift/carry

18. Number of periods with difficulty to pick up a dime

19. Number of periods with difficulty reach/extend arms up

20. Number of periods with difficulty push/pull
21. Ever experience high blood pressure

22. Ever experience diabetes

23. Ever experience cancer

24. Ever experience lung disease

25 . Ever experience heart problems

26. Ever experience stroke

27. Ever experience psychological problems

28. Ever experience arthritis

The evolving latent health index is constructed by obtaining the first principal component of all of the health indicators. The first principal component is the weighted average of the health indicators where the weights are chosen to maximize the proportion of the variance of the individual health indicators that can be explained by the first principle component. For presentation purposes we convert the first principal component into percentile scores and group persons by quintile of this score.

\section{The Relationship between Latent Health and Asset Levels and Evolution}

To explore the link between the evolving latent health index, asset levels, and asset evolution, we begin by showing illustrative results based on the raw trimmed data. We then discuss "smoothed" results based on an extension of the trimming procedure to analyze family status transitions in equation (1) above.

Figure 7-1 shows wave-to-wave changes in mean total assets for continuous two-person households in the HRS cohort by "latent health" quintile. The positive association between latent health and the level of assets is striking. Persons in the lowest $\left(5^{\text {th }}\right)$ health quintile have median total assets about half as large as persons in the top (1 $\left.1^{\text {st }}\right)$ quintile in 1992-1994 and about one-third as large in 2004-2006. Of course, the existence of a health-wealth relationship is well-known. We do not try to explain this relationship, but simply describe the relationship between the evolution of assets as people age and their latent health. 
Figure 7-1. Meantotal assets for persons age 56 to 61 in continuing two-person households in 1992, by evolving health quintile, trimmed

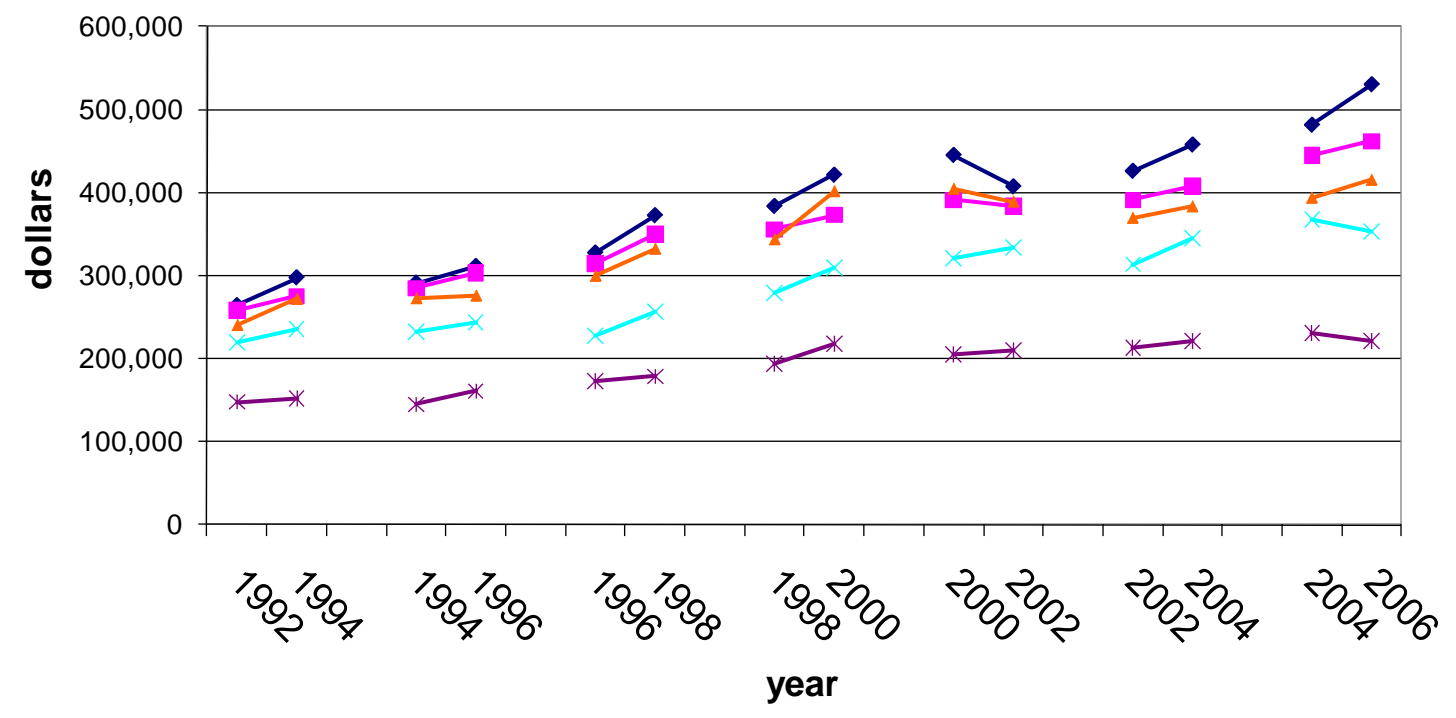

$$
\rightarrow-1 \text { st } \rightarrow-2 \text { nd } \rightarrow-3 \text { rd } * 4 \text { th } * 5 \text { th }
$$

Although the relationship between latent health and asset evolution appears quite systematic in Figure 7-1, to smooth out random fluctuations from interval to interval we parameterize the relationship between latent health and asset accumulation within each interval. The idea is not to impose a given structure on the data, but rather to smooth over randomness from interval to interval. We want a procedure that will mimic the results shown for the raw data in Figure 7-1. The parameterization is an extension of the specification shown in equation (1) above. For each family status transition group we estimate a specification of the form:

$$
\begin{aligned}
& A_{i b j}=\alpha_{b}+\sum_{j=1}^{J}\left(\delta_{b j}+\beta_{b j} h_{i}\right) I_{j}+\varepsilon_{i b j} \\
& A_{i e j}=\alpha_{e}+\sum_{j=1}^{J}\left(\delta_{e j}+\beta_{e j} h_{i}\right) I_{j}+\varepsilon_{i e j}
\end{aligned}
$$

In these equations $A$ is asset level (in constant dollars), $h$ is latent health, expressed as a percentile score, $I_{j}$ is an indicator variable for the $j$ th interval and $i, b$, and e represent, respectively, person, beginning of the interval, and end of the interval. The key feature of the parameterization is that the estimated effect of latent health is linear within each interval, but the relationship is allowed to differ from interval to interval. One restriction embodied in this specification is that the 
effect of latent health is linear with the index percentile. The same trimmed data used in the family status transition analysis above is used here. We refer to these estimates as the "smoothed" estimates.

The equations in (2) enable us to predict the beginning and ending asset levels for any latent health level and for any family status transition group. Using estimates from this specification, the estimated trimmed mean asset levels for continuing 2-person families are shown in Figure 7-2--analogous to the trimmed means without parameterizing latent health that were shown in Figure 7-1. The prediction for the first quintile (between the $80^{\text {th }}$ and $100^{\text {th }}$ percentiles) is obtained by setting $\mathrm{h}$ (latent health) to 90 percent; the prediction for the second quintile sets $h$ to 70 percent, etc. As in Figure 7-1, the influence of stock market booms and busts on the accumulation of total assets is evident. These "smoothed" estimates capture very closely the trends based on interval-by-interval estimates but without the random variation from interval to interval in the effect of latent health. The estimates for persons age 56 to 61 in 1992 in continuing twopersons households are shown in Appendix Table 7-1.

The effects of latent health are very large. The ratio of assets of persons in the top health quintile to the assets of persons in the bottom quintile is 1.7 in 1992. The assets of persons in the top quintile increased much more between 1992 and 2006 than the assets of persons in the fifth quintile. By the end of 2006 the ratio of assets in the top quintile to assets in the bottom quintile was over 2.2. The estimates for the HRS cohort age 51 to 55, shown in Figure 7-3, look much the same. In 1992, the ratio of assets in the first quintile to assets in the fifth quintile was almost 1.8. By 2006 this ratio was 2.7. 
Figure 7-2. Mean total assets for HRS persons 56 to 61 in $1992,2 \rightarrow 2$ households, by evolving health quintile, smoothed

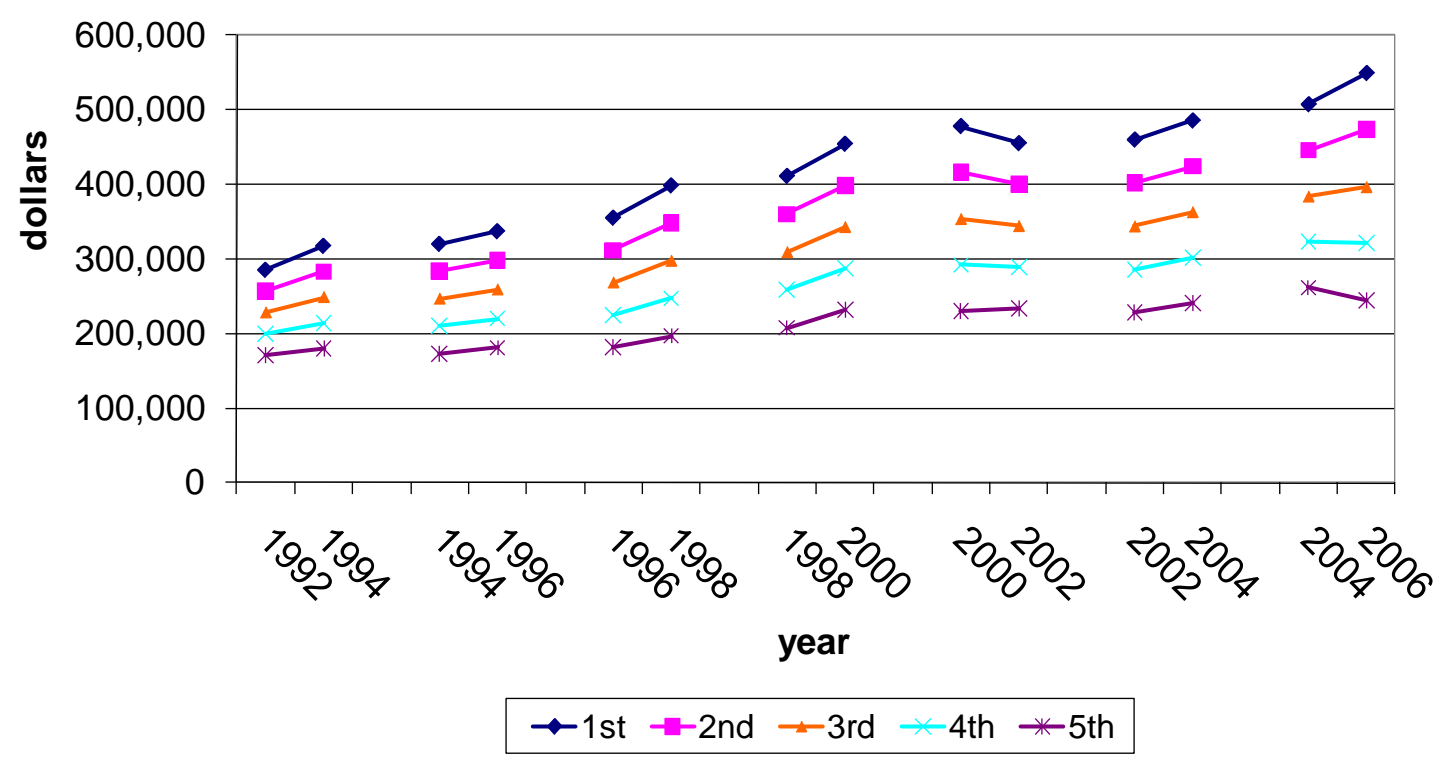

Figure 7-3. Mean total assets for persons age 51 to 55 in continuing two-person households in 1992, by evolving health

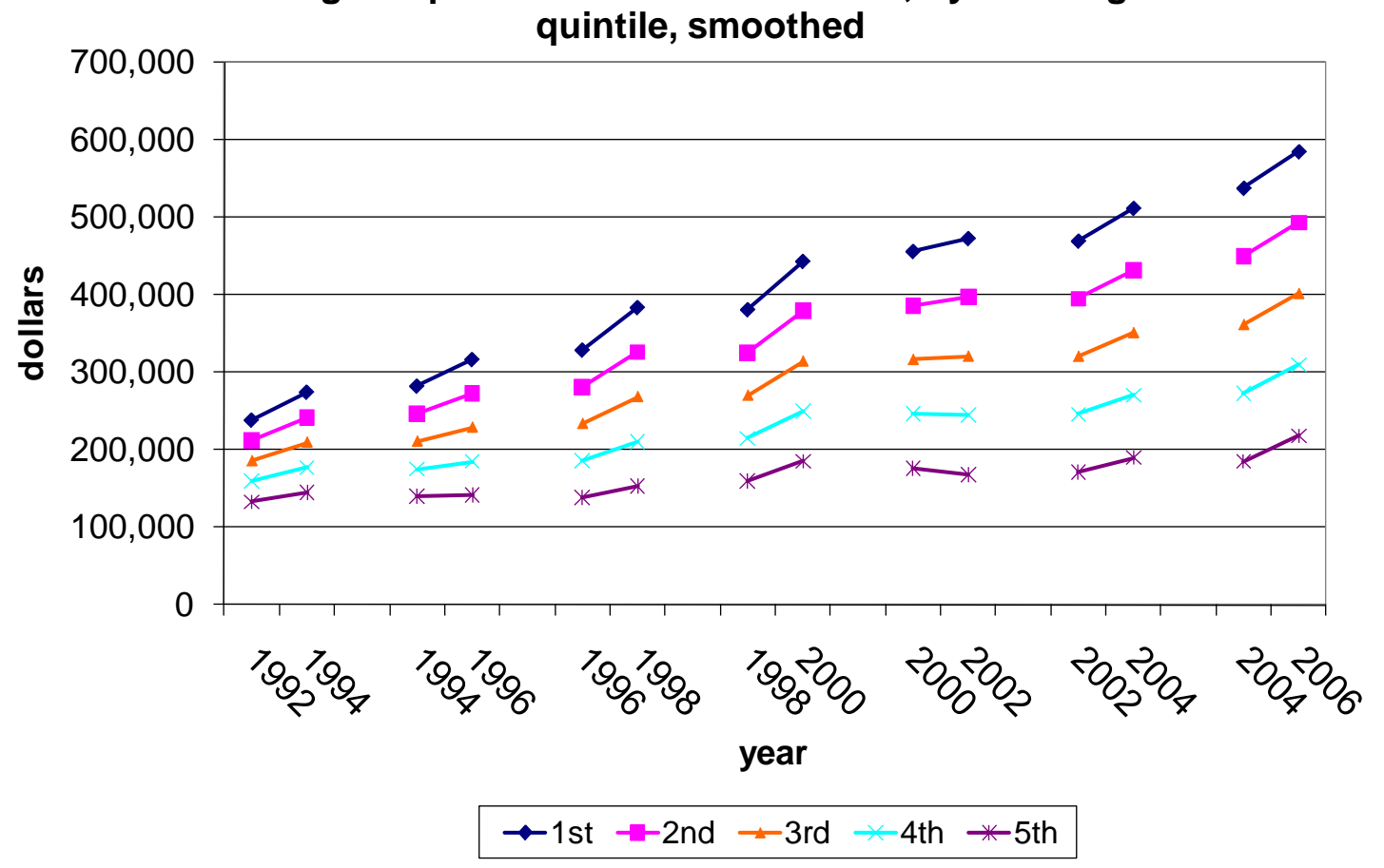


Figure 7-4. Mean total assets for AHEAD persons 70 to 75 in 1993, $2 \rightarrow 2$ households, by evolving health quintile, smoothed

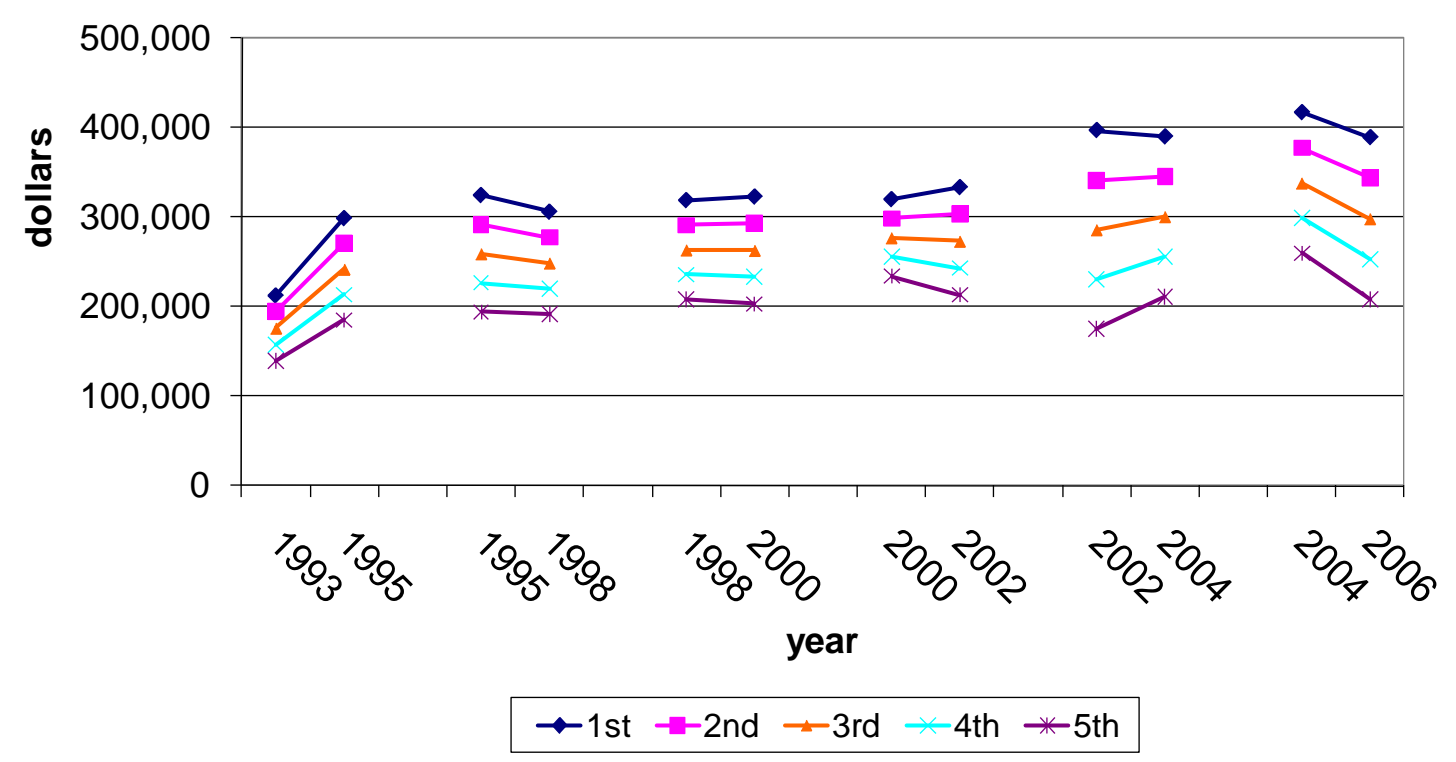

Figure 7-5. Mean total assets for HRS persons 56 to 61 in $1992,1 \rightarrow 1$ households, by evolving health quintile, smoothed

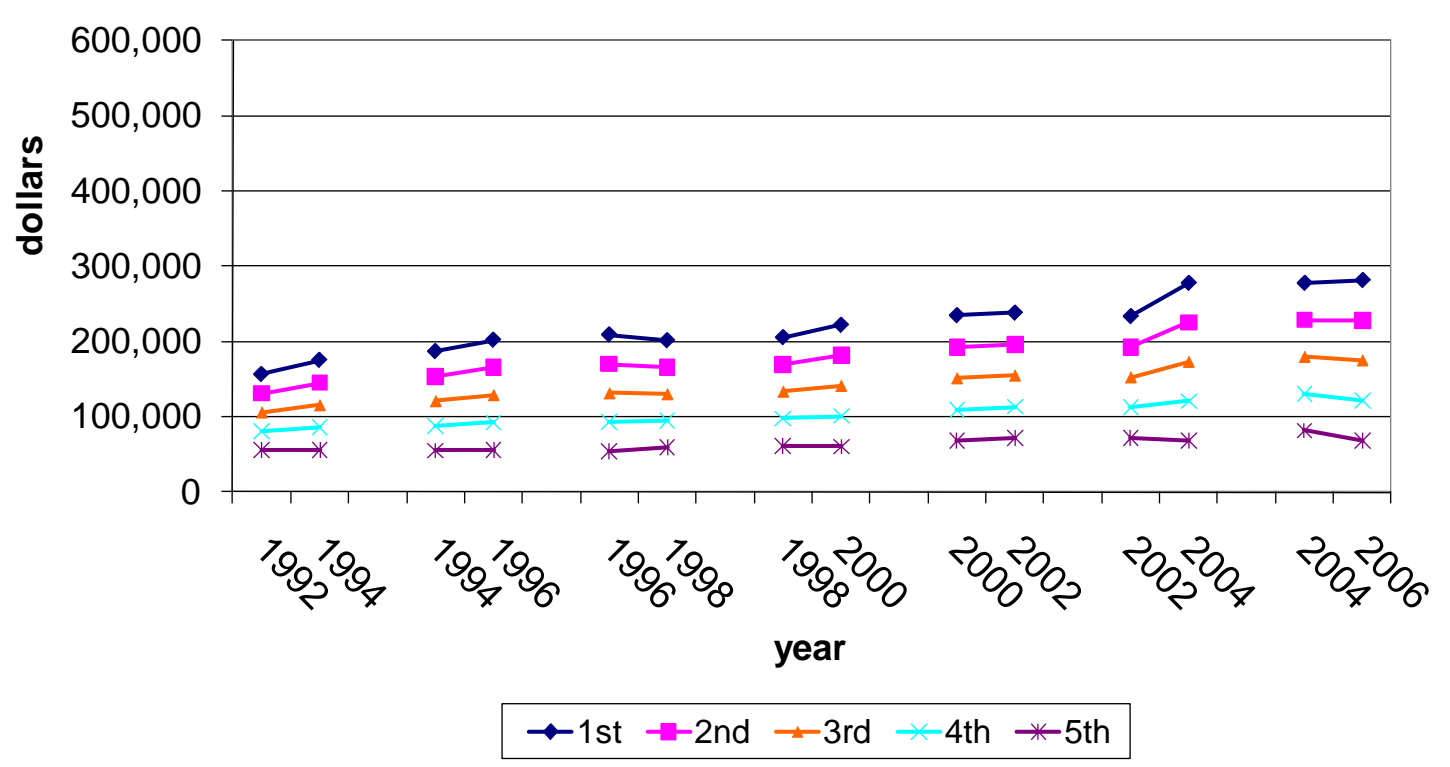




\section{Figure 7-6. Mean total assets for AHEAD persons 70 to 75 in 1993, $1 \rightarrow 1$ households, by evolving health quintile, smoothed}

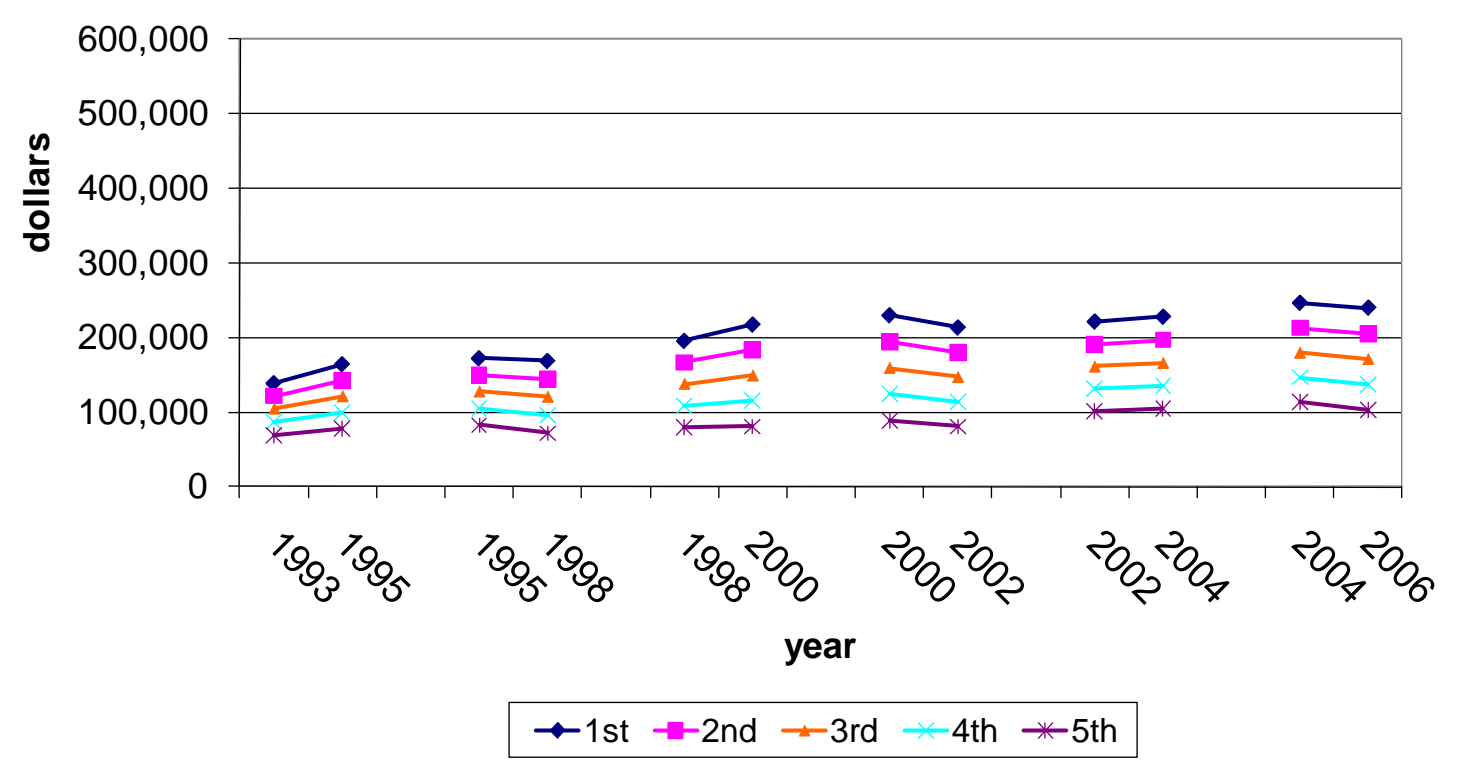

Figure 7-4 shows estimates for persons in continuing two-person AHEAD households who were age 70 to 75 in 1993. Again, the "fanning out" of profiles occurs as these persons age, but the spread is not as dramatic as for the younger cohorts. The ratio of assets in the top quintile to assets in the bottom quintile increases from 1.5 in 1993 to 1.9 in 2006. Figure 7-5 shows assets for persons age 56 to 61 in continuing one-person households in 1992 and Figure 76 show assets for persons age 70 to 75 in continuing one-person households in 1993. We have not reported latent health results for two-to-one-person transitions because the small number of observations and the confounding of data errors make the estimates very unstable.

The same sort of specification used in this section could be used to control for additional covariates such as age and gender. Controlling for age, for example, would allow us to trace out the within interval evolution of assets for any given age. But controlling for age would likely have little effect on the results that we report here for five-year age intervals. 


\section{Summary and Discussion}

In this paper, we consider the post-retirement drawdown of total assets, including housing, retirement accounts, and other financial assets. We ask how total assets evolve after retirement: whether total assets tend to be husbanded and drawn down primarily at the time of precipitating shocks. We give particular attention to the relationship between family status transitions and the evolution of assets, and the relationship between "latent" health status and the evolution of assets.

Our analysis is based primarily on HRS and AHEAD data. We organize the data so that we can observe the change in assets between each of the waves of the surveys, and we observe the changes by family status transition. Thus, we can observe the change in assets between waves for persons who continue in two-person or in one-person households between one wave and the next. This allows us to determine how asset evolution is related to family status transition. In particular, we can compare the change in assets for persons who experience a family status transition between waves with the change for persons who continue in two-person or in one-person households. In this way, we emphasize the discontinuous change in assets that accompany shocks to family status, in particular the transition from two- to one-person households.

We find several key regularities in the data. First, that the evolution of assets is strongly related to family status transitions. The total assets of continuing two-person households increase substantially well into old age. For persons aged 56 to 61 when initially observed in 1992 and aged 70 to 75 when last observed in 2006 the average (trimmed) wave-to-wave increase in total assets is 6.3 percent for continuing two-person households. For the older cohort, aged 70 to 75 in 1993 and 83 to 88 in 2006, the average(trimmed) rate of growth is 4.6 percent for continuing two-person households. For persons aged 56 to 61 when initially observed in 1992 and 70 to 75 when last observed in 2006, the average (trimmed) wave-to-wave increase in total assets is 4.2 percent for continuing one-person households. For the older cohort, aged 70 to 75 in 1993 and 83 to 88 in 2006, the average (trimmed) rate of growth is 1.4 percent for oneperson households. The median estimates tend to be smaller, but still positive with the exception of the older continuous one-person households, for whom the average increase is not significantly different from zero. In contrast, persons in households that experience a family status transition during an interval, either as a result of a divorce or the death of a spouse, often experience a large decline or no increase in total assets. Substantial declines are associated with divorce, and the declines are statistically different from zero. The total assets of persons entering widowhood increase on average but the increase is not significantly different from zero.

Second, households that experience family status transitions during an interval—widowhood or divorce-have lower levels of assets than continuing 
two-person households. The mean beginning assets of persons who will experience a family status transition are approximately 55 to 65 percent of the assets of continuing two person households. Further, these differences exist not just at the time of the transition, but are also evident long before the family transition and continue long after the transition. This finding underscores the need to account for differences in initial assets when estimating the change in assets at the time of a family status transition. Otherwise, the effects of family status transitions are confounded with prior differences in assets.

Third, the evolution of assets is very strongly related to a latent health index that we construct using principal component analysis and a range of selfreported health status measures in the HRS and AHEAD surveys. For continuing two-person HRS households aged 56 to 61 , the ratio of assets of households in the top health quintile to the assets of households in the bottom quintile is 1.7 in 1992. The assets of households in the top quintile increased more between 1992 and 2006 than the assets of households in the fifth quintile. By the end of 2006 the ratio of assets in the top quintile to assets in the bottom quintile was over 2.2. For continuing one-person HRS households aged 56 to 61 the ratio of assets of households in the top health quintile to the assets of households in the bottom quintile is 2.8 in 1992. The assets of households in the top quintile increased more between 1992 and 2006 than the assets of households in the fifth quintile. By the end of 2006 the ratio of assets in the top quintile to assets in the bottom quintile was 4.1. Similar differences are found for older AHEAD household.

Finally, we speculate about possible explanations for our results and how our results are related to recent research on the "adequacy" of saving. Households on average seem not to reduce their asset holdings in old age except at the time of changes in family status. While some might argue that this suggests that most households could have spent more before and during retirement, our results do not necessarily suggest over-saving or under-spending in retirement. If households accumulate assets to self-insure against uncertain future health shocks, then one might find many households holding stable or even rising assets over most of their retirement period. Such self-insurance was the rationale that Venti and Wise (2004) used to explain their results on the husbanding of home equity. Marshall, McGarry and Skinner (2010) make clear that out-of-pocket medical expenditures can be very large - so the potential "loss" that households may be insuring against could warrant holding substantial assets..

For similar reasons our findings do not necessarily support the view that people on average are well prepared for retirement, although they do seem to suggest better preparation than a number of other studies suggest. Hurd and Rohwedder (2009b) for example, assess saving adequacy by determining if assets at retirement are sufficient to maintain observed age-consumption profiles throughout the retirement years. Our results, however, suggest that for most types of households, assets are on average greater at age 75 than at 65 . This 
implies that if the Hurd-Rohwedder analysis was carried out at an older age, with fewer remaining years of consumption to finance and potentially higher asset levels, the results might be somewhat more encouraging about retirement saving adequacy.

We should also note that our results provide an incomplete analysis of retirement income adequacy because we do not consider alternatives to drawing down assets as a means of financing consumption in retirement. For example, we do not account for other income sources such as earnings or annuities from Social Security or defined benefit pensions. Annuity wealth is important because it affects how much non-annuity wealth needs to be drawn down in retirement. Much of our analysis focuses on the change in asset holdings over various intervals before and after retirement, and it is possible that some households with very low levels of assets are reporting increases in assets. This could generate a finding of rising asset holdings, but at a level that does not provide a substantial buffer for post-retirement financial or health shocks.

We also emphasize the empirical relationship between latent health and wealth accumulation. A number of previous studies have made formal efforts to integrate health shocks into models designed to assess the adequacy of saving-Hurd and Rohwedder (2009b), Scholz, Seshadri, and Khitatrakun (2006), and Scholz, Gale, and Seshadri (2009) are leading examples. But from the presentation of these models it is unclear how important potential future health shocks are as a source of wealth accumulation. Recent work by De Nardi, French and Jones (2006) is an exception. In their model households are shown to respond to uncertain future health costs by increasing saving. Their study does not, however, ascertain whether observed levels of wealth, though higher than they would otherwise be, are "adequate" to insure households against the financial consequences of health shocks. Laibson (2010), in the discussion comments that follow this paper, presents a more direct attempt to integrate the empirical patterns presented in this paper with a theoretical model that is capable of determining whether observed levels of wealth are "optimal." We believe there is much promise in this approach.

In future work we will address many of the issues raised in our introduction but that have not been addressed in this paper. These include an assessment of the likelihood that households will be able to cover the costs of health and family status shocks, the merits of different methods of asset drawdown, and the effect of factors such as the recent asset price decline, rising retirement ages, and the growth of personal retirement accounts on the ability to meet health and family status shocks in the future. The analysis reported here can be viewed as a starting point for these further analyses.

Finally, as emphasized above, missing data, reporting, errors, and other data limitations pose serious limitations on the analysis. In this paper, we have use medians and trimmed means to limit the influence of data errors. As we 
proceed to further analysis we will give more careful attention to correcting errors and to cross-section-longitudinal methods to check the data and fill in missing observations. 


\section{References}

Banks, James, Richard Blundell, Zoe Oldfield and James Smith. 2007. "Housing Price Volatility and Downsizing in Later Life." NBER working paper no. 13496, October.

Bosworth, Barry and Rosanna Smart. 2009. "Evaluating Micro-Survey Estimates of Wealth and Saving." Center for Retirement Research at Boston College working paper no. 2009-4.

Coile, Courtney and Kevin Milligan. 2009. "How Household Portfolios Evolve after Retirement: The Effect of Aging and Health Shocks." Review of Income and Wealth. Serios 55, No. 2. June. pp. 226-248.

Curtin, Richard., F.Thomas Juster and James Morgan. 1989. "Survey Estimates of wealth: An Assessment of Quality." In R. Lipsey and H. Tice (ed.) The Measurement of Saving, Investment and Wealth. University of Chicago Press.

Davidoff, Thomas. 2007. "Illiquid Housing as Self-insurance: The Case of LongTerm Care. Working paper.

De Nardi, Mariacristina, Eric French and John Bailey Jones. 2006. "Differential Mortality, Uncertain Medical Expenses, and the Saving of Elderly Singles," NBER Working Paper No. 12554, September.

Dushi, Irena and Marjorie Honig. 2008. "How Much Do Respondents in the Health and Retirement Study Know About Their Tax-deferred Contribution Plans? A Cross-cohort Comparison." Michigan Retirement Research Center working paper no. 2008-201.

French, Eric and John Baily Jones. 2004. "On the Distribution and Dynamics of Health Care Costs." Journal of Applied Econometrics. vol. 19, No. 4, pp 705-721.

Gustman, Alan and Thomas Steinmeier. 2004. "What People Don't Know About Their Pension and Social Security." In W. Gale, J. Shoven and M.

Warshawsky (ed.) Private Pensions and Public Policies. Brookings Institution.

Gustman, Alan and Thomas Steinmeier. 2008. "Do Workers Know Their Pension Plan Type? Comparing Workers' and Employer's Pension Information." In A. Lusardi (ed.) Overcoming the Saving Slump. University of Chicago Press.

Haveman, Robert, Karen Holden, Barbara Wolfe and Andrei Romanov. 2005. "Assessing the Maintenance of Saving Sufficiency Over the First Decade of Retirement." CESifo Working Paper No. 1567. 
Hill, Daniel. 2006. "Wealth Dynamics: Reducing Noise in Panel Data,." Journal of Applied Econometrics. Vol 21. p. 845.860.

Hurd, Michael. 2002. "Portfolios of the Elderly," in Household Portfolios (ed.) L. Guiso, M. Haliassos and T. Jappelli, MIT Press.

Hurd, Michael and Susann Rohwedder. 2006. "Life-Cycle Consumption and Wealth Paths at Older Ages," RAND Manuscript, presented at IZA Conference.

Hurd, Michael and Susann Rohwedder. 2009a. "The Level and Risk of Out-ofPocket Health Care Spending." Michigan Retirement Research Center Working Paper No. 2009-218.

Hurd, Michael and Susann Rohwedder. 2009b. "The Adequacy of Resources in Retirement, Then and Now." Presented at the AEA Meetings, Atlanta. December.

Hurst, Erik. 2008. "Consumption in Retirement: Recent Developments." In J. Ameriks and O. Mitchell, eds. Recalibrating Retirement Spending and Saving. Cambridge University Press: Pension Research Council.

Holden, Sarah and Daniel Schrass. 2009. "The Role of IRAs in U.S. Households' Saving for Retirement, 2008,". Research Fundamentals. Investment Company Institute. Vol. 18 No. 1

Juster, F. Thomas, James Smith and frank Stafford. 1999. "The Measurement and Structure of Household Wealth." Labour Economics. Vol. 6 issue 2.

Laibson, David. 2010. "Discussion," in this volume.

Lupton, Joseph and James P. Smith. 2000. "Marriage, Assets, and Savings." Working Paper.

Marshall, Samuel, Kathleen McGarry, and Jonathan Skinner. 2010. "Out of Pocket Medical Expenditures and Retirement Security in the United States," in this volume.

Megbolugbe, Issac, Jarjisu Sa-Aadu, and James Shilling. 1997. "Oh Yes, the Elderly Will Reduce Housing Equity Under the Right Circumstances." Journal of Housing Research. 8 (1): 53-74.

Megbolugbe, Issac, Jarjisu Sa-Aadu, and James Shilling. 19997. "Elderly Female-Headed Households and the Decision to Trade Down." Journal of Housing Economics. Vol. 8, p. 285-300. 
Poterba, James, Steven Venti and David Wise 2008. "Tapping Assets in Retirement: Which Assets, How, and When?" draft.

Rohwedder, Susann and Steven Haider. 2006. "Increases in Wealth Among the Elderly in the Early 1990s: How Much is Due to Survey Design? Review of Income and Wealth. Vol. 52, no. 4, December 2006.

Scholz, John Karl, Ananth Seshadri and Surachai Khitatrakun. 2006. "Are Americans Saving Optimally for Retirement." Journal of Political Economy. vol. 114, No. 4, pp. 607-643.

Scholz, John Karl, William Gale Ananth Seshadri. 2009. "Are All Americans Saving Optimally for Retirement." presented at the AEA meetings, Atlanta.

Smith, James. 1995. "Wealth Accumulation Between the Waves," paper presented at University of Michigan Workshop on HRS Surveys, November

Venti, Steven and David Wise. 2001. "Aging and Housing Equity." in Innovations for Financing Retirement (ed.) O. Mitchell, Z. Bodie, P.B. Hammond, and S. Zeldes. University of Pennsylvania Press.

Venti, Steven and David Wise. 2004. "Aging and Housing Equity: Another Look." in Perspectives in the Economics of Aging (ed.) D. Wise. University of Chicago Press. 


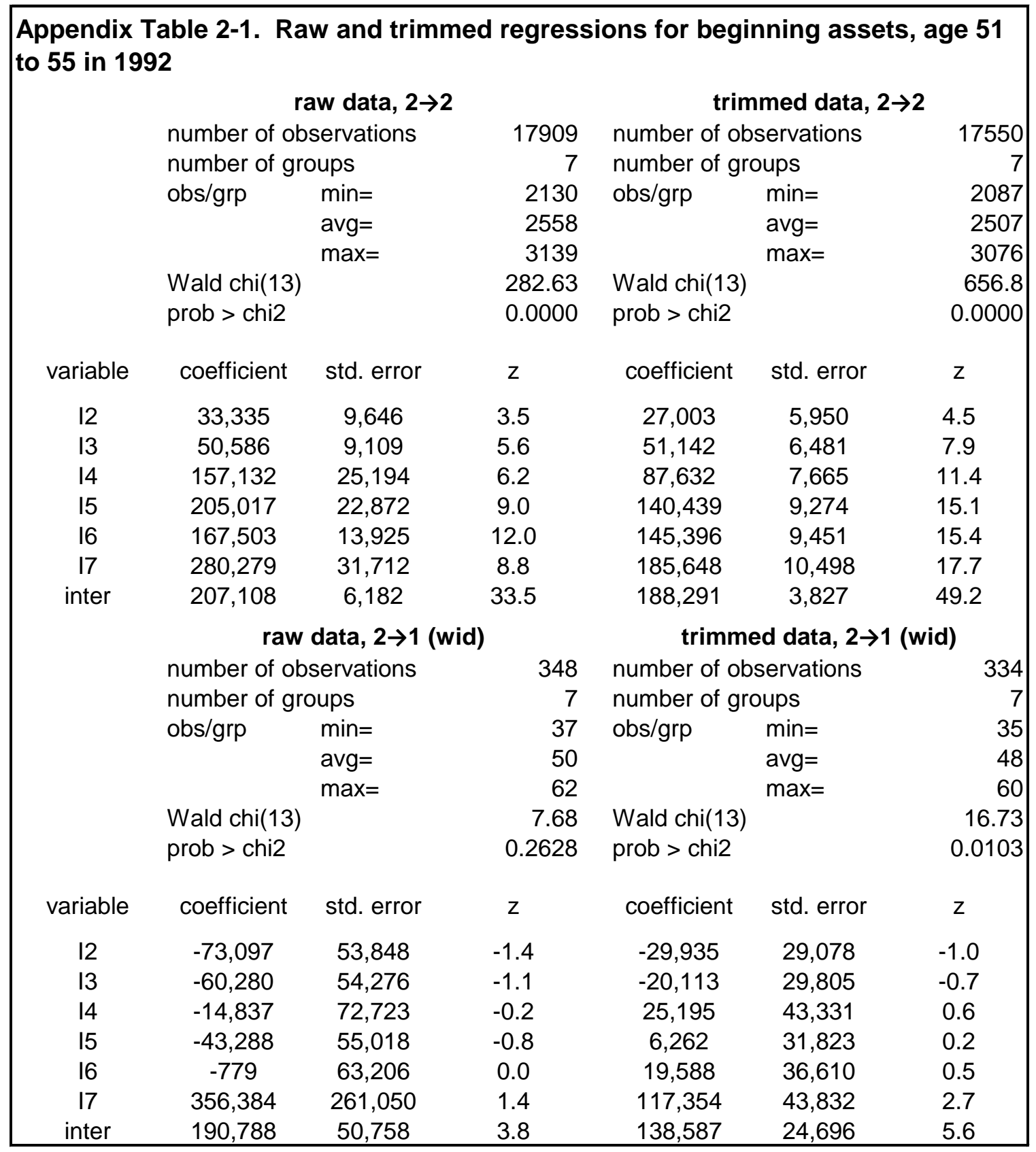




\section{Appendix Table 2-1. Raw and trimmed regressions for beginning assets, age 51 to 55 in 1992 (continued)}

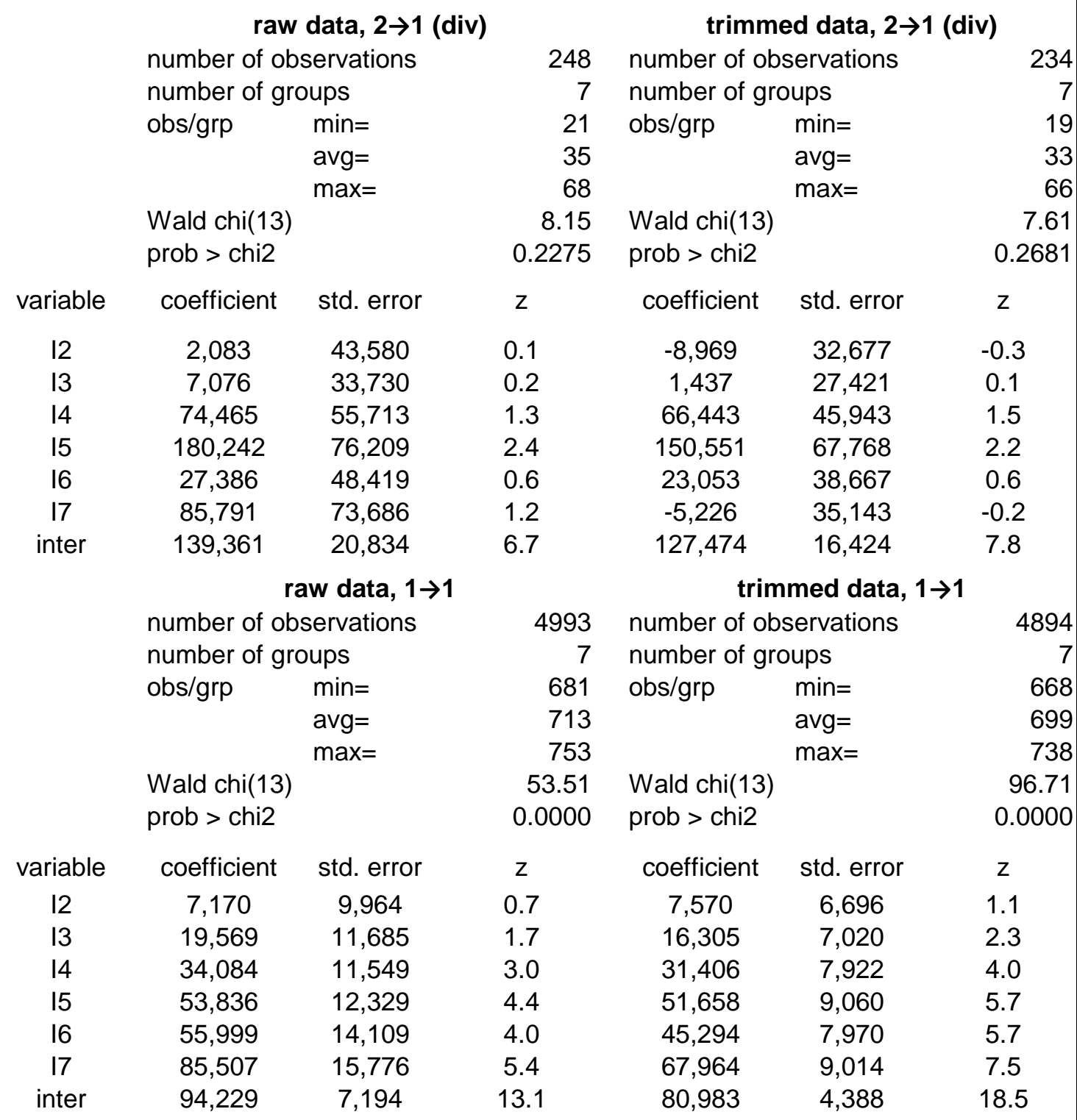

Note: Variables 12 through 17 are indicator variables for each interval. $\mathrm{H}$ is latent health expressed as a percentile score. Estimation is by generalized least squares allowing for heteroskedacity across waves. 


\begin{tabular}{|c|c|c|c|}
\hline \multicolumn{4}{|c|}{$\begin{array}{l}\text { Appendix Table 7-1. Trimmed regre } \\
\text { produce "smoothed" asset profiles } \\
\text { households }\end{array}$} \\
\hline \multicolumn{4}{|c|}{ Beginning assets, age 56-61 in 1992} \\
\hline & \multirow{2}{*}{\multicolumn{2}{|c|}{$\begin{array}{l}\text { number of observations } \\
\text { number of groups }\end{array}$}} & 17009 \\
\hline & & & 7 \\
\hline & \multirow[t]{3}{*}{ obs per group } & $\min =$ & 1834 \\
\hline & & $\operatorname{avg}=$ & 2430 \\
\hline & & $\max =$ & 3159 \\
\hline & \multicolumn{2}{|l|}{ Wald chi(13) } & 1223.9 \\
\hline & \multicolumn{2}{|l|}{ prob > chi2 } & 0.0000 \\
\hline variable & coefficient & std. error & z \\
\hline I2 & 38,881 & 12,198 & 3.2 \\
\hline I3 & 77,336 & 14,265 & 5.4 \\
\hline I4 & 137,148 & 16,087 & 8.5 \\
\hline I5 & 209,601 & 18,820 & 11.1 \\
\hline I6 & 189,438 & 18,199 & 10.4 \\
\hline I7 & 238,555 & 20,357 & 11.7 \\
\hline$I 1 * h$ & $-1,429$ & 147 & -9.7 \\
\hline$I 2 * h$ & $-1,835$ & 166 & -11.1 \\
\hline$I 3^{*} \mathrm{~h}$ & $-2,168$ & 213 & -10.2 \\
\hline $\mathrm{I} 4{ }^{*} \mathrm{~h}$ & $-2,546$ & 252 & -10.1 \\
\hline $\mathrm{I} 5^{*} \mathrm{~h}$ & $-3,101$ & 308 & -10.1 \\
\hline $\mathrm{I} 6{ }^{*} \mathrm{~h}$ & $-2,898$ & 294 & -9.9 \\
\hline $\mathrm{I} 7{ }^{*} \mathrm{~h}$ & $-3,072$ & 341 & -9.0 \\
\hline intercept & 299,503 & 8,121 & 36.9 \\
\hline \multicolumn{4}{|c|}{ Ending assets, age 56-61 in 1992} \\
\hline & \multirow{2}{*}{\multicolumn{2}{|c|}{$\begin{array}{l}\text { number of observations } \\
\text { number of groups }\end{array}$}} & 17008 \\
\hline & & & 7 \\
\hline & \multicolumn{2}{|c|}{ obs per group $\min =$} & 1834 \\
\hline & \multirow{2}{*}{\multicolumn{2}{|c|}{$\begin{array}{l}\text { avg }= \\
\max =\end{array}$}} & 2430 \\
\hline & & & 3159 \\
\hline & \multicolumn{2}{|l|}{ Wald chi(13) } & 1133.3 \\
\hline & \multicolumn{2}{|l|}{ prob > chi2 } & 0.0000 \\
\hline variable & coefficient & std. error & z \\
\hline I2 & 21,923 & 13,771 & 1.6 \\
\hline I3 & 89,098 & 15,782 & 5.7 \\
\hline I4 & 147,597 & 18,291 & 8.1 \\
\hline I5 & 148,258 & 17,827 & 8.3 \\
\hline I6 & 181,592 & 19,420 & 9.4 \\
\hline I7 & 252,778 & 22,223 & 11.4 \\
\hline $\mathrm{I} 1{ }^{*} \mathrm{~h}$ & $-1,716$ & 159 & -10.8 \\
\hline $\mathrm{I} 2 * \mathrm{~h}$ & $-1,949$ & 194 & -10.1 \\
\hline$I 3 * h$ & $-2,518$ & 238 & -10.6 \\
\hline $\mathrm{I} 4{ }^{*} \mathrm{~h}$ & $-2,779$ & 292 & -9.5 \\
\hline $\mathrm{I} 5^{*} \mathrm{~h}$ & $-2,765$ & 281 & -9.8 \\
\hline$I 6 * h$ & $-3,057$ & 313 & -9.8 \\
\hline $\mathrm{I} 7^{*} \mathrm{~h}$ & $-3,805$ & 373 & -10.2 \\
\hline intercept & 334,525 & 8,757 & 38.2 \\
\hline \multicolumn{4}{|c|}{$\begin{array}{l}\text { Note: Variables } 12 \text { through } 17 \text { are indicator variables for each } \\
\text { interval. } \mathrm{H} \text { is latent health expressed as a percentile score. } \\
\text { Estimation is by generalized least squares allowing for } \\
\text { heteroskedacity across waves. }\end{array}$} \\
\hline
\end{tabular}

